Portland State University

PDXScholar

10-1994

\title{
An Empirical Assessment of the Gentrification Process in Northwest Portland, Oregon
}

Sabrina Oesterle

Portland State University

Follow this and additional works at: https://pdxscholar.library.pdx.edu/open_access_etds

Part of the Demography, Population, and Ecology Commons, Inequality and Stratification Commons, and the Race and Ethnicity Commons

Let us know how access to this document benefits you.

\section{Recommended Citation}

Oesterle, Sabrina, "An Empirical Assessment of the Gentrification Process in Northwest Portland, Oregon" (1994). Dissertations and Theses. Paper 3533.

https://doi.org/10.15760/etd.5417

This Thesis is brought to you for free and open access. It has been accepted for inclusion in Dissertations and Theses by an authorized administrator of PDXScholar. Please contact us if we can make this document more accessible: pdxscholar@pdx.edu. 


\section{THESIS APPROVAL}

The abstract and thesis of Sabrina Oesterle for the Master of Arts in Sociology were presented August 9, 1994, and accepted by the thesis committee and the department.

COMMITTEE APPROVALS:
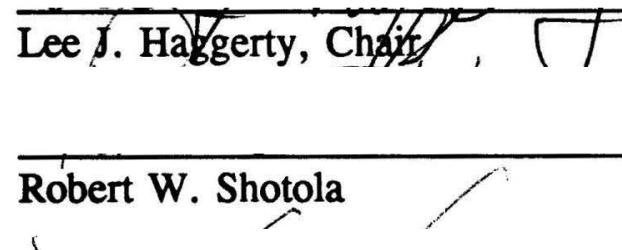

Maria Wilson-Figueroa

James G. Strathman

Representative of the Office of Graduate Studies

DEPARTMENT APPROVAL:

Robert W. Shotola, Chair

Department of Sociology

ACCEPTED FOR PORTLAND STATE UNIVERSITY BY THE LIBRARY

bys

on 6 llitake $194 x$ 


\begin{abstract}
An abstract of the thesis of Sabrina Oesterle for the Master of Arts in Sociology presented August 9, 1994.
\end{abstract}

Title: An empirical assessment of the gentrification process in Northwest Portland, Oregon.

Since the late 1960s and early 1970s, many American cities experienced the process of gentrification, and there are many studies based on data from this time period. A first purpose of this study was to follow up on the development of gentrification in the 1980s. Northwest Portland, Oregon, is culturally clearly defined as a gentrifying neighborhood and was, therefore, chosen as to empirically assess this process by comparing the 1980 with the 1990 census data.

There is some theoretical confusion about the concept of gentrification. There is, however, general consensus on two aspects. The first is a physical renovation of old and run-down inner-city neighborhoods, and the second is a change in the demographic composition of the revitalizing neighborhood from low and middle to upper-middle and high status residents. One aspect of gentrification is largely ignored by empirical studies, but often assumed to flow from physical renovation and compositional change, i.e. an alteration in the fabric of social life in the 
gentrified area, in patterns of interaction and symbolic attachment. It was a second purpose of this study to explore this issue on the basis of longitudinal survey data collected in the Northwest neighborhood in 1978 and 1993.

The census analysis showed that the demographic change in Northwest Portland was surprisingly consistent with Gale's original stage model of gentrification from 1980, but not with predictions for more recent times. The analysis of the survey data showed a lack of overall change in the interactional and symbolic fabric of community life. T-tests for distinct life-cycle stages and socioeconomic status showed a perception of the Northwest neighborhood as a nicer and safer place for all groups. The young were found to form a community consistent with the model of a "community of limited liability." Specifically for older and highincome residents it is proposed that the demographic change, which made the neighborhood more status homogeneous, had an important socially integrating impact, consistent with Claude Fischer's notion of "critical mass" creating viable subcultures, since they were found, in opposition to common expectations, to have increased attachment and social contacts in the neighborhood. 


\section{AN EMPIRICAL ASSESSMENT OF THE GENTRIFICATION PROCESS IN NORTHWEST PORTLAND, OREGON}

by

SABRINA OESTERLE

A thesis submitted in partial fulfillment of the requirements for the degree of

\section{MASTER OF ARTS \\ in SOCIOLOGY}

Portland State University

1994 
DEDICATION

To my father and my mother 


\section{ACKNOWLEDGEMENTS}

Most of all, I want to thank Dr. Lee J. Haggerty who introduced me to the field of urban sociology and is responsible for my enthusiasm in this field. He did a great job as my thesis adviser. He was always very helpful and his ideas and suggestions always solved my problems. Most important for a project like this, he was always very fast in reading and correcting my drafts. In addition, I learned a lot about quantitative methods from him. With his encouragement, I knew I could do it.

I also want to thank Dr. Robert W. Shotola who made it easy for me as an exchange student to get started in the program and who supported my idea of doing this thesis from the start. His excitement about my progress during the thesis work was an encouragement for me.

I also want to mention the entire sociology department, the faculty and my fellow students, who made this a very enjoyable year and who gave me valuable insight into American sociology and culture. 


\section{TABLE OF CONTENTS}

\section{PAGE}

ACKNOWLEDGEMENTS $\ldots \ldots \ldots \ldots \ldots \ldots \ldots \ldots$ iv

LIST OF TABLES $\ldots \ldots \ldots \ldots \ldots \ldots \ldots \ldots \ldots \ldots \ldots \ldots \ldots$

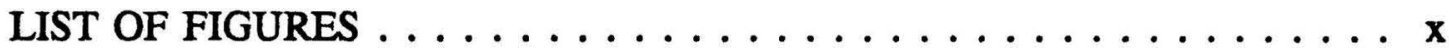

\section{CHAPTER}

I INTRODUCTION $\ldots \ldots \ldots \ldots \ldots \ldots \ldots \ldots$

II THEORETICAL BACKGROUND $\ldots \ldots \ldots \ldots \ldots \ldots$

III THE NORTHWEST NEIGHBORHOOD AND

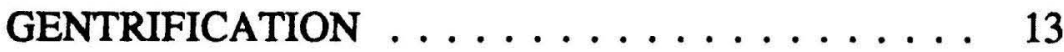

IV COMPOSITIONAL AND ECOLOGICAL

CHANGE IN THE NORTHWEST IN

THE 1980s . . . . . . . . . . . . . . . . 21

Socioeconomic characteristics $\ldots \ldots \ldots 22$

Education

Occupation

Income

Other compositional shifts . . . . . . . . . . 28

Household composition

Age structure

Gender

Shifts in ecological patterns . . . . . . . . . . 43 
Geographic mobility

Proximity of home and workplace

Residential segregation

V CHANGES IN INTERACTIONAL AND

SYMBOLIC FEATURES OF THE

NORTHWEST NEIGHBORHOOD . . . . . . . . 50

Theoretical models and expectations $\ldots \ldots \ldots . .50$

Data and measures $\ldots \ldots \ldots \ldots \ldots \ldots$

Survey data

Measures

Findings $\ldots \ldots \ldots \ldots \ldots \ldots \ldots \ldots \ldots$

Demographic, interactional, and attitudinal profile of the neighborhood

Analysis

VI SUMMARY AND CONCLUSIONS $\ldots \ldots \ldots \ldots \ldots \ldots$

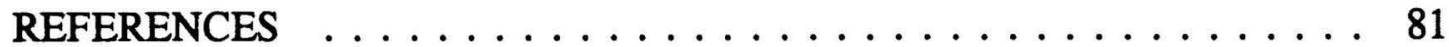

\section{APPENDICES}

A AGE COHORT TABLES $\ldots \ldots \ldots \ldots \ldots \ldots$

B CODEBOOK AND INDEX VARIABLES $\ldots \ldots \ldots \ldots$

C CORRELATION TABLES $\ldots \ldots \ldots \ldots \ldots$ 


\section{LIST OF TABLES}

TABLE

PAGE

I Educational achievement of persons 25 years and older, 1980 and $1990 \ldots \ldots \ldots 23$

II

Professional, managerial, executive, and administrative occupations of employed persons 16 years and over, 1980 and $1990 \ldots \ldots \ldots \ldots \ldots$. . . . . . . . . . . 25

III Blue-collar workers, employed persons 16 years and over, 1980 and $1990 \ldots \ldots$. . . . . 25

IV

Median and mean household income in the Northwest, 1979 and $1989 \ldots \ldots 27$

V Household income in the Northwest, 1979 and $1989 \ldots \ldots \ldots \ldots \ldots \ldots$. . . . . . . . . . 28

VI Household composition, 1980 and $1990 \ldots \ldots \ldots \ldots$

VII Double-income families, 1980 and $1990 \ldots \ldots \ldots 32$

VIII Median age of all persons and of females, 1980

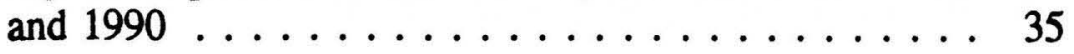

IX Ratio of actual to expected numbers of persons in age cohorts in 1990 for the city and the Northwest ................ 38

X Single females and single mothers, 1980 and $1990 \ldots \ldots \ldots \ldots \ldots \ldots \ldots \ldots$. . . . . . . 41

XI Females in labor force and females unemployed, 1980 and $1990 \ldots \ldots \ldots 41$ 
XII Female householders, no husband present below poverty level, 1980 and $1990 \ldots \ldots$. . . 42

XIII Residence five years ago of persons 5 years or older, 1980 and $1990 \ldots \ldots \ldots$. . . . . . 44

XIV Mean travel time to work in minutes for workers 16 years and over, 1980 and $1990 \ldots \ldots \ldots \ldots \ldots \ldots$. . . . . . . . . . 46

XV $\quad$ Race, 1980 and $1990 \ldots \ldots \ldots \ldots \ldots$

XVI Life-cycle stages of survey respondents in the Northwest neighborhood, 1978 and

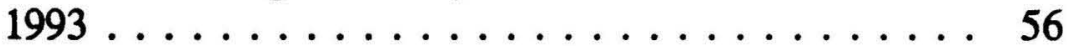

XVII Statistically significant differences between 1978 and 1993 in means of neighboring, satisfaction, and attachment measures, all persons . . . . . . . 61

XVIII Statistically significant differences between 1978 and 1993 in means of neighboring, satisfaction, and attachment measures, young individuals .................. 64

XIX Statistically significant differences between 1978 and 1993 in means of neighboring, satisfaction, and attachment measures, young couples . . . . . . 65

XX Statistically significant differences between 1978 and 1993 in means of neighboring, satisfaction, and attachment measures, young families . . . . . . 65

XXI Statistically significant differences between 1978 and 1993 in means of neighboring, satisfaction, and attachment measures, single parents $\ldots \ldots \ldots 66$ 
TABLE

PAGE

XXII Statistically significant differences between 1978 and 1993 in means of neighboring, satisfaction, and attachment measures, old individuals . . . . . . . . 67

XXIII Statistically significant differences between 1978 and 1993 in means of neighboring, satisfaction, and attachment measures, old couples . . . . . . . . . 68

XXIV Actual and expected numbers of persons in age cohorts in 1990 for the city of Portland ................ 88

XXV Actual and expected numbers of persons in age cohorts in 1990 for the Northwest neighborhood . . . . . . . . . . . . . . 89

XXVI Actual and expected numbers of females in age cohorts in 1990 for the Northwest neighborhood .................. 90

XXVII Statistically significant correlations of education with neighboring, satisfaction, and attachment measures in 1993 compared to $1978 \ldots \ldots 101$

XXVIII Statistically significant correlations of income with neighboring, satisfaction, and attachment measures in 1993 compared to $1978 \ldots \ldots \ldots \ldots$. . . . . . . . . . . . 102 


\section{LIST OF FIGURES}

1. Boundaries and location of Northwest District and census tract 47 in Portland, Oregon. . . . . . . . . . . . . . . 15

2. Factors influencing neighborhood attachment. ....... 51 


\section{CHAPTER I}

\section{INTRODUCTION}

Gentrification first appeared and was recognized by urban sociologists in the late 1960s and early 1970s in several American cities. Since then, many cities all over the country experienced this process. The term gentrification involves several processes and there is some theoretical confusion about this concept. There is, however, general consensus on two aspects of gentrification. The first is the physical renovation of old and run-down inner-city neighborhoods, in the beginning by private, later also by commercial investment, and the second is a change in the demographic composition of the revitalizing neighborhood from low and middle status residents to upper-middle and high status residents. A third aspect of gentrification, that is largely ignored by empirical studies, but often assumed to flow from physical renovation and compositional change, is an alteration in the fabric of social life in the gentrified area, in patterns of interaction and symbolic attachment.

There are several other processes interwoven with these basic processes. The renovation of the old housing stock, eventually, results in increasing property values and housing costs. Low-income residents are often forced out of the neighborhood as they cannot afford the rising housing values and rents anymore. Finally, they are displaced by higher-income households that have the necessary resources at their 
disposal. Studies disagree as to the extent of displacement attributed to gentrification. The problem with studies of displacement is the measurement of the motivations of residents to move out. It is not clear if the out-movers actually are displacees, i.e. if they moved involuntarily. At least, displacement studies show that those who said that they moved involuntarily are generally renters. These studies also demonstrate that especially minorities, old people, and female householders with children are the most vulnerable to displacement, since these groups are more likely to be poor (Gale 1984). However, displacement per se was not examined in this thesis, since my focus was on compositional changes in general and, finally, on changes in the fabric of social life.

Revitalizing areas are typically located close to downtown and characterized by architecturally appealing Victorian homes that offer, in the beginning of the process, cheap housing in the heart of the city. The first, widely known, and most typical example of a gentrifying neighborhood in Portland, Oregon was Northwest Portland. A brief history of this neighborhood and the development of gentrification there, as it was presented in the local media, is described in chapter III.

Since most of the existing gentrification literature described the revitalization of many American city-core neighborhoods during the late 1960s and early 1970s, the 1990 census data, which became available in 1993, made it possible to follow up on the development of gentrification in the 1980s. In chapter IV, I describe the compositional and ecological change that occured during the 1980s in the Northwest neighborhood as analyzed by a comparison of the 1990 census data with the 1980 
census data.

The existing gentrification research literature had another shortcoming that I explored using Northwest Portland as a case study. While demographic changes in gentrifying areas were a main issue in gentrification research, changes in interactional and symbolic features of the neighborhood were usually not considered. The interactional and symbolic community refers to social contacts between neighbors and the attachment of residents to their neighbors and the neighborhood. Chapter $\mathrm{V}$ explores this issue on the basis of an analysis of survey data collected in the Northwest neighborhood in 1978 and 1993. A summary of the findings of the analyses in chapter IV and V and some questions for the future are presented in chapter VI.

The following chapter gives a theoretical background and a review of the existing literature on gentrification and interactional and symbolic aspects of community.

Some of the limitations of this thesis resulted from the usage of secondary data which were originally not intended to serve my specific purposes. The reader should also be cautious, since the survey data contained relatively low numbers of respondents. 


\section{CHAPTER II}

\section{THEORETICAL BACKGROUND}

Gentrification is a widely investigated process in urban sociology. A multitude of case studies, comparative studies, and theoretical approaches exist from the 1970s and the 1980s. Nevertheless, there are still "questions about the full extent and significance of gentrification" (Hutchison 1992, p. 6) which need to be investigated. Not only Hutchison (1992), but also Spain (1992) see the opportunity to find answers in using the now available 1990 census data for further research.

Spain (1992) also points out: "It is [the] complexity that makes gentrification worth continued attention in the 1990s" (p.125). The complexity of the gentrification process lies not only in the diverse patterns that occur throughout different cities, but especially in its "chaotic conception" (Beauregard 1986; Rose 1984; Warde 1991). While Warde (1991) calls for a synthesis of the diverse theoretical approaches to gentrification, Spain (1992) argues that "[i]ntellectual consensus is not as important as the need to broaden, rather than narrow, our conceptualizations of the phenomenon" (p. 132).

Warde (1991) detects four types of processes which are subsumed under one label: (1) "a process of displacement of one group of residents with another of higher social status," (2) "a transformation in the built environment," (3) "a 
gathering together of persons with a putatively [italic by S.O.] shared culture and life-style," and (4) "an economic reordering of property values" (p. 225). What the term "gentrification" usually means is a coincidence of all these processes.

Gale (1980) suggests a stage theory of gentrification. He argues that gentrifying neighborhoods change demographically over three time phases (see also Pattison 1983; Clay 1979). These stages are distinguished by different groups of inmovers, the risk-oblivious, the risk-prone, and the risk-averse. Throughout the three stages, in-movers are going to be increasingly professionals, managers, and administrators; educational attainment and income increase; especially the risk-averse in-movers in the last stage are more likely to have children; and the new residents are increasingly from the suburbs. With the changing demographic characteristics of the residents their attitudes toward the neighborhood will change as well. They are more likely to be committed to long-term residence and to be more critical of the condition of the neighborhood and the available services.

Kerstein (1990) found in his study of Tampa, Florida, consistency with most of the demographic changes predicted in the stage model, whereas most of the predictions for attitudinal changes were not clearly supported. In particular, he found, in contrast to Gale's expectations, that in-movers in a later stage of gentrification were least likely to have children and that most of the new residents moved from within the city or the same neighborhood. He concludes that "it is possible that differing characteristics of the neighborhoods, not just the stage of revitalization that each was in, affected in-mover characteristics and attitudes" (p. 
623). He, therefore, supports Beauregard's argument, too, that gentrification is a chaotic concept, "involving diverse processes in different contexts" (Kerstein 1990, p. 635).

Because most of the gentrification studies examine the time period between 1970 and 1980, little is known about the specific development in the 1980s. Spain (1992) suggests five specific hypothesis which can serve in evaluating more recent levels of gentrification activity. The five hypotheses are: (1) gentrification activity will be reduced, since the large source of gentrifiers, that is the baby boom generation, ages and is now in the stage of forming families and therefore likely to move out of the city, (2) women are more likely to be displacees than gentrifiers, because they are statistically more likely to be poor than wealthy, (3) residents of gentrified neighborhoods are more likely to have shorter journeys to their work place than other residents in the city, (4) the gentrified neighborhood becomes racially more heterogeneous, and (5) conflict in urban and rural communities increases as inmovers have greater resources than long-term residents. I, specifically, used the first four hypotheses to guide the examination of the census data for the Northwest neighborhood in Portland, Oregon (see chapter IV).

In contrast to early "classic" theories about urban social life as superficial , transitory, and impersonal, in which the individual is alienated and emotionally isolated and has secondary rather than primary relationships (Tönnies [1887] 1957; Simmel [1905] 1950; Park 1915; Wirth 1938), newer neighborhood research draws a different conclusion than predicted (e.g. Suttles 1972; Hunter 1974, 1978; Guest 
and Lee 1983; Varady 1986). These studies found that neighboring, neighborhood attachment, and primary local ties do exist in the modern city. Nevertheless, other studies (Fischer 1973; Woolever 1992) seem to validate Wirth's theory to a certain extent, since they find density as "consistently predictive of lower social involvement, dissatisfaction with the neighborhood and weaker ties of attachment" (Woolever 1992, p.111).

On the other hand, Fischer (1975) states "With size comes 'community'" (pp. 1328/29). Only the large and heterogeneous populations of cities can yield "critical masses" necessary to create and maintain "unconventional subcultures" (p. 1320). He defines "subculture" as "a set of modal beliefs, values, norms, and customs associated with a relatively distinct social subsystem (a set of interpersonal networks and institutions) existing within a larger social system and culture" (p. 1323). The subculture's behavior is unconventional, comparable to deviant behavior "except that it incorporates also less socially significant (and unstigmatized) behavior, that in the realm of taste or style" (pp. 1323/24). These subcultures are characterized by certain demographic traits of its members, such as occupation, social class, and life-cycle stage.

Applied to the issue of gentrification, I prefer Fischer's description of the self-selective formation and spatial concentration of a certain sub-group of people as a depiction of the demographic change in a gentrifying area, rather than the mostly used expression of the emergence of a "new middle class." In the case of a gentrifying neighborhood, the emerging subculture is formed by the "yuppies", the 
"young upwardly mobile professionals of the baby boom generation" (Smith 1987, p. 151), who share a lifestyle of conspicuous consumption and orientation toward their personal careers.

Continuing from the gentrification literature that proposes changing demographic characteristics of residents of the neighborhood throughout the gentrification process, I want to include literature about neighboring that sees the different attributes of residents as possible predictors for a certain neighboring behavior. Haggerty's study (1982) considers different explanations for social contact in urban areas. Those are (1) an ecological explanation mainly represented by the Chicago School of Urban Sociology, (2) a sociodemographic explanation, and (3) a combination of the two explanations above. Haggerty's results from an analysis of the 1970 census data for eight neighborhoods in Portland, Oregon, indicate that a combined explanation is the most credible, but that the physical and social environment of a neighborhood influences "only the most casual and overt forms of neighboring" (p. 359) as waving and chatting to neighbors, while differences in more intense contacts are better explained by sociodemographic characteristics of the residents.

Most of the studies about neighboring behavior only consider sociodemographic traits. This literature is divided into two positions: one side sees the life-cycle stage of the residents as the main influence on neighboring (Greer 1962; Athanasiou and Yoshioka 1973; Philliber 1976), while the other side emphasizes Social Economic Status (SES) as the main predictor for neighboring 
behavior (Lynd and Lynd 1929, 1937; Gans 1962; Hunter 1974). Also, the direction of the relation between SES and neighboring is controversial. One camp views SES as positively related to neighboring behavior (Lynd and Lynd 1929, 1937), what Hunter (1974) calls the "valued community" approach. The mass community approach asserts a negative relation between SES and neighboring (Stein 1960; Gans 1962; Wamer 1963). Advocates of the life-cycle explanation found familism, i.e. marriage and presence of children in the household, as positively related to neighboring.

Campbell and Lee (1990), in addition to the category of gender included, both life-cycle and SES in their study of possible influences on neighboring. What they found is that gender is the most powerful predictor of the three, i.e. "women neighbor more than men" (Campbell and Lee 1990, p. 506). Still, SES and life-cycle stage both are positively related to neighboring behavior, but affect different forms of neighboring. They found a positive relation between education and the number of neighbors known by name, and between income and the number of close friends in the neighborhood, and also the total number of intimates in the neighborhood (i.e. close friends, kin, and co-workers). They found that married persons had more close friends and more co-workers living in the neighborhood than singles. The presence of children had no effect.

Campbell and Lee (1992) also studied neighbor networks, using the same differentiation of life-cycle and SES. Their findings parallel the results in their previous study of neighboring behavior. Specifically, they found that women had 
larger networks than men, i.e. they knew more neighbors by name and talked to or visited with more neighbors. Marriage, education, and income increased the network size, too. Presence of children in the household, again, did not make a difference. They also considered age in this study. Their expectation of a curvilinear relation between age and neighbor networks, where young and old persons are rather marginal and middle-aged persons are overall socially more integrated, was supported.

As in the case of gentrification research, there are also many studies from the last two decades about neighborhood satisfaction and attachment. One important conceptual distinction was made by Guest and Lee (1983a) and also Ringel and Finkelstein (1991). They found that satisfaction and attachment have to be distinguished, but that they are closely related. Specifically, satisfaction represents an evaluation of the physical environment of the neighborhood, while attachment derives from physical and social integration and is a sentiment rather than a rationale (Ringel and Finkelstein 1991). Satisfaction with the neighborhood shows a perception of the local area as "a nice place to live", what Guest and Lee (1983b) call a "community of limited liability" (Greer 1962; Janowitz 1967), while attachment is an affectual attraction to the neighborhood even with a low level of satisfaction (Ringel and Finkelstein 1991), which comes closest to Guest and Lee's (1983b) definition of an "urban village." A more detailed explanation of these community types will be given later.

It was found that several factors influence the level of attachment. One 
important factor is the satisfaction with the personal safety and the physical and social environment (Marans and Rogers 1975; Miller, Tsemberis, Malia, and Grega 1980; Herting and Guest 1985; St. John, Austin, and Baba 1986; Austin and Baba 1990). Other factors are participation in formal and informal activities in the neighborhood (Kasarda and Janowitz 1974; Hunter 1982; St. John et al. 1986; Woolever 1992) and social integration (i.e. length of residence and number of friends in the neighborhood) (St. John et al. 1986). The attachment to a neighborhood is also influenced by compositional characteristics of individual residents (Lee and Guest 1983), directly and also indirectly through the three factors satisfaction, social integration, and participation (St. John et al. 1986; Austin and Baba 1990; Woolever 1992). Compositional variables are, for example, socioeconomic status, race, age, presence of children, and home-ownership.

Woolever (1992) considers in her study of neighborhood attachment not only individual (compositional and interactional) characteristics of residents, but also contextual characteristics of the neighborhood, such as status differences, density, and heterogeneity. Status is included as a factor, since "it is hypothesized that residents of all status levels tend to adopt the orientation of their environment" (p. 102). The measurement of heterogeneity is included, because homogeneity is seen as "the principal basis of attachment and interaction" (p. 103). Her findings support these hypotheses.

While Woolever (1992) found the city center neighborhoods of her study in Indianapolis, Indiana, consistent with the "natural community" model of the Chicago 
School (Park, Burgess, and McKenzie 1925), or, in Guest and Lee's (1983b) terms, with the "urban village", a gentrified neighborhood, specifically, seems to be better described by the "community of limited liability" model, originally thought to apply especially to suburbs. "Thè limited liability model views the local community as a site for meeting the interests and needs of selected population groups in a stratified, bureaucratized society" (Guest and Lee 1983b, p. 222). The commitment to the neighborhood in the case of the "limited liability model" is not emotional and personal as in the "urban village," but a commitment by personal interest and by formal and informal participation in the neighborhood. A "community of limited liability" was found to be an area with high housing values, high status residents, and a place where children have been raised. A "natural area" is particularly characterized by population stability, intimate social relations, and wide performance of functional activities within the neighborhood (Guest and Lee 1983b). Residents in a community of limited liability were found to define their neighborhoods as "physical territories" and to show satisfaction with housing, safety, and people, thus perceiving the areas as "nice places in which to live" (Guest and Lee 1983b, p. 235) rather than showing strong feelings of attachment. In chapter V, I consider the applicability of the "limited liability model" to the case of the Northwest neighborhood. 


\section{CHAPTER III}

\section{THE NORTHWEST NEIGHBORHOOD AND GENTRIFICATION}

Northwest 23rd Avenue is hot. Check it out on any weekend afternoon and you will find swarms of hip-looking shoppers peering into the windows of eclectic shops with intriguing names - Dazzle, Itchy Fingers, In the Bag (McDermott 1990).

This newspaper account is a good example of the wide perception of the Northwest neighborhood in the late 1980s and early 1990s as a "yuppie" place, a place where the "cashmere crowd" likes to "brunch 'n' browse" (Moerer 1983), where you can find "the crowd that grazes on brie and prosciutto at Ron Paul Charcuterie or skims the specialty magazines at Rich's Cigar Store" (Mc Dermott 1990). However, the neighborhood has not always been like this. Starting in the early 1970s, gentrification:

has stamped a new personality on a neighborhood known for charming Victorians and grass-roots organizers, scrappy tabloids and troublesome taverns. [...] Cafe latte and croissants are replacing beer and pretzels as the refreshment of choice, Ralph Lauren has a greater cachet than Levis Strauss, and there's hardly a neighborhood denizen or little old lady to be seen on a Saturday afternoon (McDermott 1990).

Historically, the Northwest neighborhood was described as one of "the city's

first developed neighborhood[s]" (Mantia 1976). Mantia (1976) reports that it was Captain John Couch, "one of Portland's early pioneers" (p.13), who started the 
neighborhood with the purchase of a large tract of land between the Willamette River and 21st Avenue in the 1880s. At the turn of the century, the north part of the neighborhood - "Slabtown" - was occupied by immigrants, mainly Scandinavians and Serbo-Croatians, who worked in the sawmills at the river (Pintarich 1972; Mantia 1976). "The area got its name from the mounds of wood slabs piled up in front of homes -the slabs were used to fire wood stoves" (Mantia 1976). "Nob Hill" in the south part of the neighborhood was inhabitated by "wealthy and established Portlanders" (Pintarich 1972) in nice Victorian houses. Particularly, NW 19th Avenue became the neighborhood's exclusive area with large mansions.

The Northwest neighborhood is adjacent to the Central Business District (CBD) and is bounded by NW Nicolai Street to the north, NW 16th Avenue to the east, W Burnside to the south, and Westover/Cornell Road at the foot of Willamette Heights to the west (see figure 1).

Diversity was the main characteristic of the Northwest neighborhood that was mentioned throughout all the accounts in local newspapers in the 1970s - "One description of Northwest Portland that even its own residents can agree upon," wrote Lee Perlman in 1974 in the Willamette Week. The neighborhood was diverse referring to the mixture of its land uses:

The neighborhood is a strange hodgepodge of 1890 s Victorian houses, 1920s stucco apartments, Gothic cathedrals, hospitals and convalescent homes, all beefed up by a strong business district along NW 21st and 23rd avenues (Mantia 1976). 


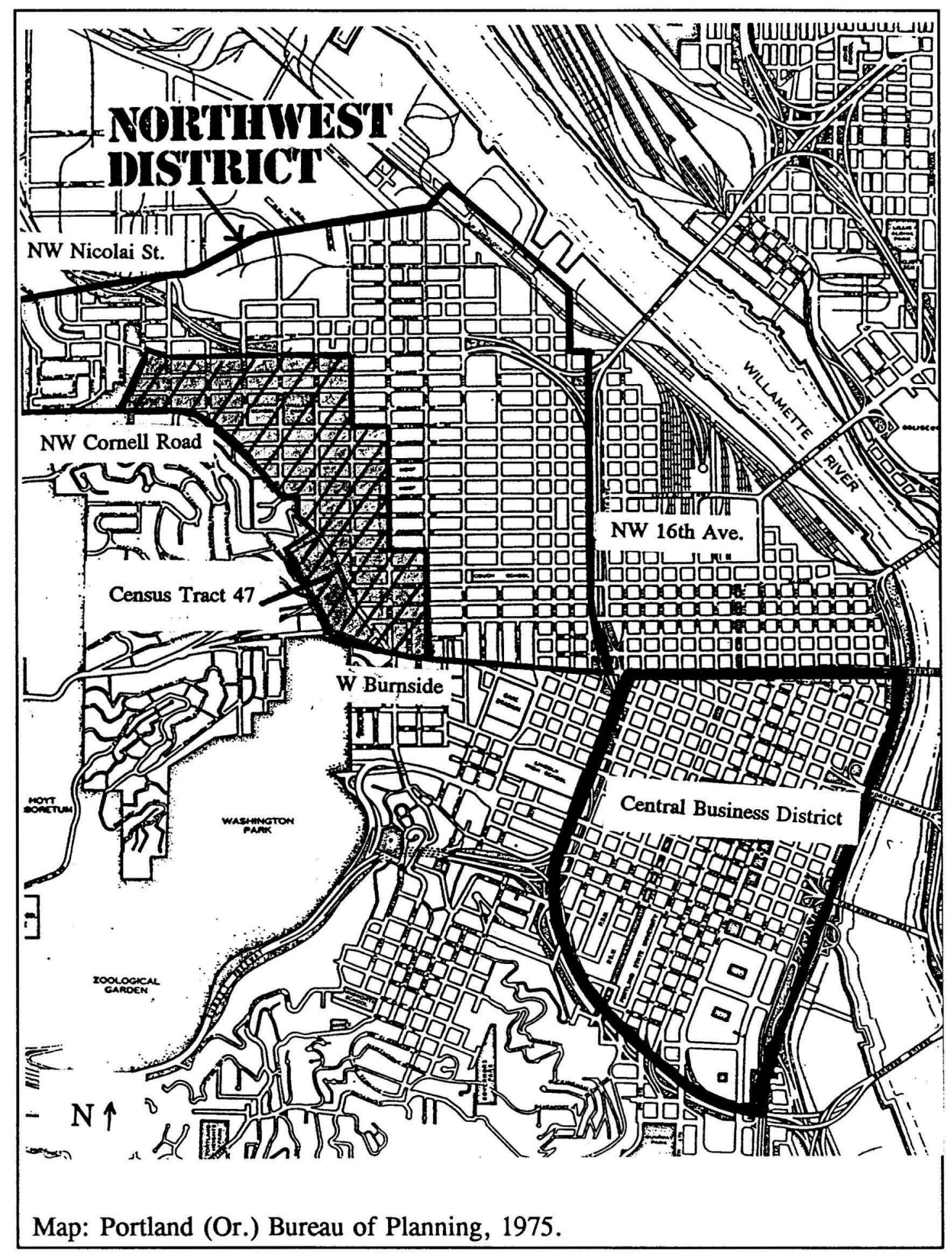

Figure 1. Boundaries and location of Northwest District and census tract 47 in Portland, Oregon. 
However, most of the once splendid Vitorian homes became delapidated and decimated during the 1950s and 1960s. The neighborhood had the highest residential density in Oregon and became a low-rent area for, particularly, young and old persons on fixed incomes. The middle-aged and middle-income families with children who owned their homes left the neighborhood during that time and moved to the newly built suburbs. More than 80 percent of the residents in the Northwest neighborhood were renters. The loss of residential units was due to land conversions to commercial and industrial areas and the expansion of Good Samaritan Hospital. Some saw also land speculation as a major cause, where property was bought up and left to deteriorate "in the hope of selling it for a profit or converting it to some more profitable use" (Perlman 1974). In addition, the neighborhood was threatened by a plan to build a freeway through the north section of the neighborhood.

In 1970, the Northwest District Association (NWDA) and city planners began to conduct extensive studies in order to find solutions to the problems the neighborhood was facing. After 18 months, in March 1972, the Northwest Comprehensive Plan was presented, "essentially a plea for survival of the urban neighborhood" as Paul Pintarich commented in The Oregonian, March 19, 1972. The plan outlined several major goals:

Reverse the present trend toward the loss of housing, preserve and enhance services and facilities for residents, diversify the population and increase the number of childrearing families and maintain and strengthen citizen groups (Pintarich 1972).

Specifically, recommended actions to reach these goals were to stimulate ownership through tax relief, improve and strengthen residential areas by re-zoning the 
neighborhood, provide social services and programs for residents, reduce traffic, get cars off the streets, improve mass transit through new street routing, establish pedestrian and bikewalks, and improve parks. The proposed re-zoning included "down-zoning from business to residential" (Residents seek neighborhood improvement, 1972), the creation of a "design zone" "to preserve historical landmarks, old homes, trees and the general atmosphere of congenial urbanity" (Residents seek neighborhood improvement, 1972), maintaining the "commercial zone" on NW 21st and 23rd avenues, and "Qualified Zoning", to eliminate land speculation. Social services and programs should be "aimed at creating a greater sense of meaning and purpose in the lives of residents, principally the aged and poor, but drawing in the young and family groups for human interaction" (Residents seek neighborhood improvement, 1972). Diversity was seen as particularly important, since "Diversity is the essence of urban living; without it the reason for city life hardly exists" (Residents seek neighborhood improvement, 1972).

The Northwest Comprehensive Plan proposed by the NWDA was then countered by a proposal of the Northwest Improvement Committee (NWIC), the industrial lobby in the neighborhood. In 1974, The Oregonian reported: "NWDA says 'downzone'; businessmen yell" (Perlman 1974). The review of the plans by the Planning Commission resulted in the recommendation of a compromise plan, which was finally adopted in July 1975 and issued in the "Northwest District Policy Plan" by the Portland Bureau of Planning.

In the mid-1970s, "Northwest neighborhood group activists feel they have 
turned this trend [of deterioration and age polarization] around" (Mantia 1976), as the neighborhood gradually started to experience an influx of the middle-aged, single-family home-owners, and families with children, who began a "restoration revival" (Mantia 1976). But also young adults, students at downtown Portland State University, and artists were attracted by the changing characteristic of the neighborhood and the architecturally nice, but old buildings, which provided cheap rents. It was more and more described as a place of "porch sitters" who had "many little public sidewalk contacts" (Mantia 1976), a place where "everyone knows everyone else" (Pattison 1976), and where people were committed to the area. The Northwest neighborhood started to become a place with many alternative life-styles. A cooperative grocery store with organically grown food located on NW Thurman street, an artists' community formed, and young people lived together in communes and smoked marijuana (Patterson 1976). "Parry Pittman, one of three coordinators of the Food Front Cooperative Grocery, $[. .$.$] , says the neighborhood has a free spirit$ because of 'free-spirited people who live loose, casual, spontaneous lives'" (Patterson 1976).

However, while the revitalization activity in the neighborhood went on, attracting more businesses such as boutiques and restaurants and more and more people with higher incomes, life in Northwest Portland began to exhibit new problems. "The Northwest is experiencing the greatest change at the most rapid pace [of revitalizing areas in Portland], and, because it's the most densely populated area in the city, the changes have inevitably led to conflicts" (Moerer 1983). Parking and 
traffic were some of the more manifest problems. A more subtle problem was increasingly the integration of old and new residents who were quite different from each other. "[F]or all the outward changes in the neighborhood - including the influx of what seems like half the city's young professionals - the bulk of the neighborhood's population is still older and poorer than the citywide average" (Moerer 1983). Older and poorer residents and small neighborhood shops and services had to fear rising property values, that made the more negative aspects of gentrification, such as displacement, the leading topic in the media in the late 1980s and early 1990s. Allen Classen, editor and publisher of The Examiner, a monthly neighborhood newspaper, said that:

they [the residents] admit the neighborhood is more lively and interesting because of the shops. This neighborhood is very liberal, tolerant and progressive. But even the merchants when they talk about gentrification think first about the problems of squeezing out longtime residents (McDermott 1990).

And also Lee Perlman reported in 1992 in The Oregonian: "Northwest Portland residents like the neighborhood they have, but don't want more boutiques, row houses and gentrification." So the neighborhood association Neighbors West/Northwest became active and started to work on a new project, the "Northwest Infill Project:"

It will be a demonstration project for the Portland Bureau of Planning's Livable Cities Project, which is trying to demonstrate how increased density can be accomodated while preserving the character of neighborhoods. (Perlman 1992)

Another problem arose, too. "A rash of burglaries and vandalism appears to 
be the result of underlying economic class antagonism," was the summary headline in The Oregonian on May 29, 1992. Anonymously written "anti-gentrification fliers", exclaiming "Our actions are aimed at you, the rich, the upper class" (McVea 1992), frightened businesses and residents, and clearly demonstrated that the neighborhood was not as satisfying and attractive anymore to some people, presumably renters displaced by rising housing costs, as some believed (McVea 1992).

In recent times, the Northwest neighborhood seems to have lost some of the attractiveness that it gained during the early revitalization phase in the 1970 s, as "[r]esidents say the relentless crime, coupled with parking problems, aggressive panhandlers and transients, is diminishing the pleasure of living in the neighborhood" (McVea 1992). 


\section{CHAPTER IV}

\section{COMPOSITIONAL AND ECOLOGICAL CHANGE IN THE NORTHWEST IN THE 1980s}

Although a great deal of research about gentrification has been done in the past two decades, there is still a lot of confusion about the concept of gentrification. There is no consensus of the causes of gentrification, the characteristics of gentrifiers, or the assessment of the result. That is why gentrification is often referred to as a "complex" process that is not the same in different cities, in different areas of the United States, or in other parts of the world.

In order to assess the level of gentrification in the Portland Northwest neighborhood in the most recent decade, I particularly took four of Spain's (1992) hypotheses and tested them by analyzing the 1990 census data in comparison with the census data of 1980. As presented in chapter II, Spain expected for the more recent time period that gentrification activity will be reduced as the baby boom generation enters a more familistic life-cycle stage, that women are rather displacees than gentrifiers, that residents of gentrified areas have a shorter journey to work, and that the gentrified area becomes racially more heterogeneous. In addition, I examined changes in socioeconomic characteristics of residents, i.e. occupation, education, and income, because these attributes are main indicators for the presence 
of gentrifiers (see e.g. Gale 1984).

The area of analysis was the census tract 47 which has the same boundaries in 1980 as in 1990 (see figure 1). It is comparable to the Northwest District's subarea "Hills and Westside" (Portland Bureau of Planning, 1975). My focus in the analysis of the census data was on changes in demographic characteristics of the Northwest neighborhood in comparison to the city of Portland (Multnomah County only) in general.

\section{SOCIOECONOMIC CHARACTERISTICS}

\section{Education}

An increasing level of resident's educational attainment seemed to be the most consistent indicator for gentrification activity (Gale 1984; Smith 1987; Warde 1991). The majority of the studies of gentrifying areas found that the proportion of residents with high levels of education increased and the proportion of residents with low educational attainment decreased. I, therefore, compared the proportion of persons with a college degree ${ }^{1}$ in the Northwest neighborhood in the years 1980 and 1990.

The result clearly supports the hypothesis of increasing educational attainment levels. While the proportion of persons with a college degree in the city overall

${ }^{1}$ The census categorization of educational attainment differs in the years 1980 and 1990. I took the category "4 or more years of college" in 1980 as comparable to "Bachelor's degree or higher" in 1990. 
increased by $17.2 \%$, it increased by $35.1 \%$ in the Northwest. The proportion in the Northwest increased therefore two times more than that in the city. In 1990, half of the persons living in the Northwest neighborhood had at least a college degree. In the city, only about a fourth of the residents had a college degree or more (see table I).

TABLE I

EDUCATIONAL ACHIEVEMENT OF PERSONS 25 YEARS AND OLDER, 1980 AND 1990

\begin{tabular}{ccccc}
\hline & 1980 & 1990 & $\begin{array}{c}\text { change } \\
1980 \text { to } 1990\end{array}$ & $\begin{array}{c}\text { ratio }{ }^{2} \text { of \% } \\
\text { change in the NW } \\
\text { to \% change in the } \\
\text { city }\end{array}$ \\
\hline $\begin{array}{c}\text { college degree or higher } \\
\text { City }\end{array}$ & $22.1 \%$ & $25.9 \%$ & $+17.2 \%$ & 2.041 \\
\hline Northwest & $37.6 \%$ & $50.8 \%$ & $+35.1 \%$ & \\
\hline $\begin{array}{c}\text { less than 9 years of } \\
\text { schooling }\end{array}$ & & & & \\
\hline City & $11.7 \%$ & $5.6 \%$ & $-52.1 \%$ & 1.299 \\
\hline Northwest & $9.3 \%$ & $3.0 \%$ & $-67.7 \%$ & \\
\hline
\end{tabular}

Source: Adapted from Census of Population and Housing, 1980, Table P-1, and Census of Population and Housing, 1990, Table 1.

Compared to the proportion of persons with a college degree, the proportion of persons with less than 9 years of schooling decreased in the city overall as it did

${ }^{2}$ This ratio is the quotient of the percentage change in the Northwest divided by the percentage change in the city. If the direction of change is opposite, the quotient is negative. This applies to all following tables of this kind. 
in the Northwest neighborhood, though the decrease in the Northwest was 1.3 times higher than in the city. The proportion of persons with less than 9 years of schooling decreased by $67.7 \%$ in the Northwest and by $52.1 \%$ in the city (table I). This outcome further sustains the hypothesis of a gain of persons with high levels of education and a loss of persons with low educational attainment in a neighborhood that experienced gentrification.

\section{Occupation}

Previous research found that revitalizing areas particularly attract a rising proportion of persons with professional, managerial, executive, and administrative occupations. In general, with an increasing level of gentrification white-collar workers replace blue-collar workers.

The analysis of the census data for the occupational status of residents resulted in findings that are consistent with this hypothesis. Professional, managerial, executive, and administrative occupations increased by $39.9 \%$ in the Northwest between 1980 and 1990 , while these types of occupations increased by only $14.1 \%$ in the city overall. The increase in the Northwest was therefore 2.8 times higher than in the city (see table II).

The change in the proportion of blue-collar workers was as predicted. The Northwest neighborhood experienced a $35.7 \%$ decrease in blue-collar workers between 1980 and 1990 as opposed to a small decrease of $4 \%$ in the city overall (see table III). Accordingly, I see the expectation for changes in occupational status as 
convincingly reinforced for the case of the Northwest neighborhood.

TABLE II

PROFESSIONAL, MANAGERIAL, EXECUTIVE, AND ADMINISTRATIVE

OCCUPATIONS OF EMPLOYED PERSONS 16 YEARS AND OVER, 1980 AND 1990

\begin{tabular}{lllcl}
\hline 1980 & 1990 & $\begin{array}{c}\text { change } \\
1980 \text { to } 1990\end{array}$ & $\begin{array}{c}\text { ratio of \% } \\
\text { change in the NW } \\
\text { to \% change in the } \\
\text { city }\end{array}$ \\
\hline City & $25.6 \%$ & $29.2 \%$ & $+14.1 \%$ & 2.830 \\
\hline Northwest & $33.1 \%$ & $46.3 \%$ & $+39.9 \%$ & 2.00 \\
\hline
\end{tabular}

Source: Adapted from Census of Population and Housing, 1980, table P-10, and Census of Poplation of Housing, 1990, table 18.

TABLE III

BLUE-COLLAR WORKERS ${ }^{a}$, EMPLOYED PERSONS 16 YEARS AND OVER, 1980 AND 1990

\begin{tabular}{lllll}
\hline 1980 & 1990 & $\begin{array}{c}\text { change } \\
1980 \text { to } 1990\end{array}$ & $\begin{array}{c}\text { ratio of \% } \\
\text { change in the NW } \\
\text { to \% change in the } \\
\text { city }\end{array}$ \\
\hline City & $40.4 \%$ & $38.8 \%$ & $-4.0 \%$ & \\
\hline Northwest & $37.0 \%$ & $23.8 \%$ & $-35.7 \%$ & 8.925 \\
\hline
\end{tabular}

Source: Adapted from Census of Population and Housing, 1980, table P-10 and Census of Population and Housing, 1990, table 18.

a Blue-collar workers=private household, protective service, service (except protective and household), farming, forestry, and fishing, precision production, craft, and repair, transportation and material moving occupations, machine operators, assemblers, and inspectors, handlers, equipment cleaners, helpers, and laborers. 
Income

The gentrification literature suggests that median household incomes in gentrifying areas increase at a higher rate than in the city overall. More middle- and upper-middle income households move into the neighborhood, while lower-income households move out.

The comparison of income in dollars, income categories, and income distributions at two points of time, though, caused some difficulties. The problem was that the dollar amounts of the mean and median income in the census are not adjusted for inflation. The income categories changed, too, because the entire distribution was pushed upwards. There were more people who earned more than $\$ 50,000$ in 1990 than in 1980 just due to the effect of inflation. In the 1990 census, the 1980 category of "\$50,000 and more" was further decomposed into three categories, i.e. " $\$ 50,000$ to $\$ 74,999 ", " \$ 75,000$ to $\$ 99,999 "$, and $" \$ 100,000$ and more" which were combined in table $V$ to make the comparison between 1980 and 1990 possible. Further, because dollar amounts were not comparable over the years, median and mean income, and the income classes were not normed on the year 1980 , but they were expressed as a percentage of the city.

When I compared the census data on median household income for the Northwest in 1979 and 1989 (see table IV), I found that the hypothesis was supported to the extent that the income gap between the city overall and the Northwest neighborhood had narrowed. The median household income in the Northwest in 1989 was still lower than in the city, but in 1979 it was lower by 
$25.1 \%$ compared to only $5.2 \%$ in 1989 .

I found the same outcome when I compared the mean household income, yet the expected shift was more clear. While the mean income in the Northwest was lower, i.e. only $87.6 \%$ of that in the city overall in 1979 , it was higher than in the city in 1989 by $5.4 \%$.

TABLE IV

MEDIAN AND MEAN HOUSEHOLD INCOME IN THE NORTHWEST, 1979 AND 1989

\begin{tabular}{ccccc}
\hline & 1979 & & 1989 & \\
\hline $\begin{array}{c}\text { Median } \\
\text { Income }(\$)\end{array}$ & $\begin{array}{c}\text { \% of City } \\
\text { Median }\end{array}$ & $\begin{array}{c}\text { Median } \\
\text { Income }(\$)\end{array}$ & $\begin{array}{c}\text { \% of City } \\
\text { Median }\end{array}$ \\
\hline 11,071 & 74.9 & 24,255 & 94.8 \\
\hline $\begin{array}{c}\text { Mean } \\
\text { Income }(\$)\end{array}$ & $\begin{array}{c}\text { \% of City } \\
\text { Mean }\end{array}$ & $\begin{array}{c}\text { Mean } \\
\text { Income }(\$)\end{array}$ & $\begin{array}{c}\text { \% of City } \\
\text { Mean }\end{array}$ \\
\hline 16,129 & 87.6 & 35,122 & 105.4 \\
\hline
\end{tabular}

Source: Adapted from Census of Population and Housing, 1980, table P-11 and Census of Population and Housing, 1990, table 19.

When I compared income classes for the gentrifying area, I found that the proportion of middle-income households in the Northwest increased between 1979 and 1989 relative to the city, while the proportion of lower-income and high-income households decreased in the same time period (see table V).

Especially, the proportion of households with incomes of $\$ 15,000$ to $\$ 24,999$ and with incomes of $\$ 25,000$ to $\$ 34,999$ increased at a higher rate in the Northwest, i.e. the data showed increases of $52.4 \%$ and $28.8 \%$, respectively. However, the 
proportion of households with incomes less than $\$ 5,000$ decreased by $48.9 \%$ relative to the city. These findings clearly support the hypothesis that the gentrifying neighborhood attracted mainly middle- and upper-middle income households and lost lower-income households.

\section{TABLE V}

HOUSEHOLD INCOME IN THE NORTHWEST, 1979 AND 1989

\begin{tabular}{|l|c|c|c|}
\hline $\begin{array}{c}\text { Household income in the } \\
\text { Northwest }\end{array}$ & $\begin{array}{c}\text { (1) } \\
\text { \% of city } \\
\text { proportion in } \\
1979\end{array}$ & $\begin{array}{c}\text { \% of city } \\
\text { proportion in } \\
1989\end{array}$ & $\begin{array}{c}\text { \% change from } \\
1979 \text { to } 1989\end{array}$ \\
\hline Less than $\$ 5,000$ & 124.4 & 63.6 & -48.9 \\
\hline$\$ 5,000$ to $\$ 9,999$ & 140.2 & 125.7 & -10.3 \\
\hline$\$ 10,000$ to $\$ 14,999$ & 90.7 & 94.3 & +4.0 \\
\hline$\$ 15,000$ to $\$ 24,999$ & 73.5 & 112.0 & +52.4 \\
\hline$\$ 25,000$ to $\$ 34,999$ & 79.9 & 102.9 & +28.8 \\
\hline$\$ 35,000$ to $\$ 49,999$ & 81.4 & 75.2 & -7.6 \\
\hline$\$ 50,000$ or more & 118.9 & 106.3 & -10.6 \\
\hline
\end{tabular}

Source: Adapted from Census of Population and Housing, 1980, table P-11 and Census of Population and Housing, 1990, table 19.

\section{OTHER COMPOSITIONAL SHIFTS}

According to Spain (1992), demographic variables have an important function when assessing the level of gentrification in a neighborhood. She emphasized the role of young, childless households as the major source of demand for gentrified 
housing. Her main hypothesis was that the gentrification activity will be reduced in the 1980 s, because the baby boom generation, which poured onto the housing market in the 1970s and created a significant demand for dwellings, is now aging and in the stage of family formation. Because older people and families with children are more likely to move to the suburbs and the cohorts born after the baby boom cannot provide the critical mass of young gentrifiers the gentrification process is slowed down.

Household composition

The literature attributes certain prevalent household compositions to a gentrifying neighborhood, i.e. particularly persons living alone and childless couples (Le Gates and Hartman 1981; Gale 1984; Kerstein 1990; Spain 1992). Young families with children are usually not among the gentrifiers.

The comparison of the census data for the two years 1980 and 1990 on household composition is presented in table VI. It shows that three forth of all householders in the Northwest neighborhood lived in non-family households, among them about $80 \%$ lived alone. This remained stable over the time period between the years 1980 and 1990 . In the city, by comparison, only slightly more than $2 / 5$ of the householders lived in non-family households, but more than half (about 56\%) of them lived in family households compared to $24 \%$ in the Northwest. As in the Northwest, this general situation in the city overall remained stable. This first result clearly represents the expectation that gentrifying areas do not attract families. 
However, a closer look at different family types revealed a different picture (table VI). When I compared married-couple, female-headed, and male-headed families with and without children at home, I found significant shifts in the household composition in the two areas. It is striking that all shifts in the Northwest were the reverse of that in the city overall. While the proportions of all family types, except married-couple families, in the city overall increased, they decreased in the Northwest neighborhood. In addition to the opposite direction of the change in the gentrifying area, most of the change was also greater than in the city overall.

In particular, although the predominant family form in the Northwest neighborhood was married-couple families without children at home, the proportion of married-couple families with children at home increased by an outstanding $45 \%$. This was a 35 times greater change than in the city overall. This contradicts Spain's hypothesis that the aged baby boom cohort will not be as attracted to inner-city neighborhoods because it is now in the family formation stage. Quite to the contrary, the northwest neighborhood was not very attractive to persons living alone and families in general, but it clearly attracted families with children at home which indicates an advanced stage of gentrification.

It has been suggested that the so called Dinks, i.e. "double-income-no-kids" households play an important role in gentrification (Le Gates and Hartman 1981; Smith 1987; Warde 1991). However, it was previously documented that the proportion of couples with children increased significantly in the Northwest 


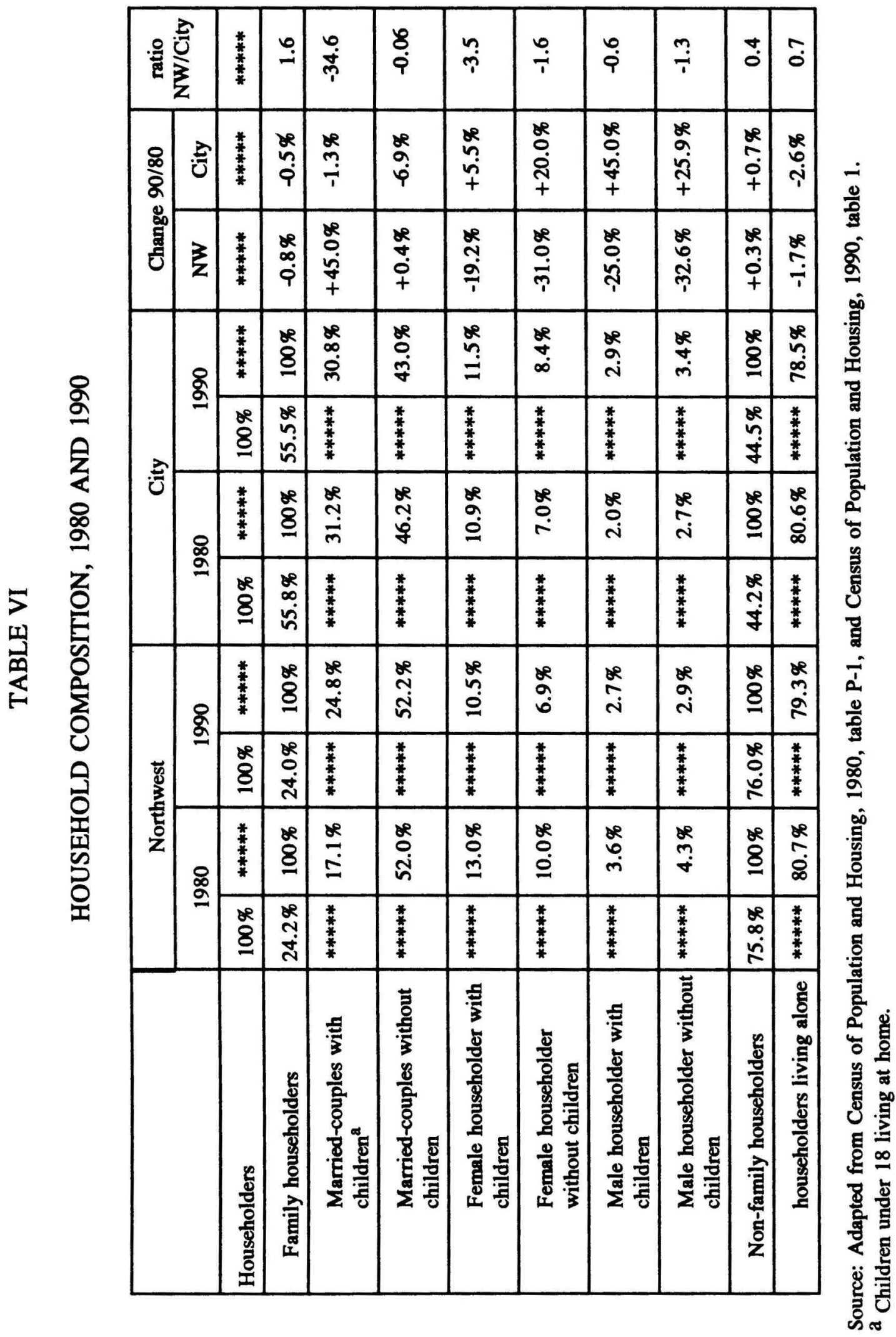


neighborhood. This questions the role of the "no-kids"-part of double-income households for gentrification, but what happened to the number of workers in these households? Unfortunately, it was not possible to crosstabulate census data on the tract level. This was one major disadvantage when using census data. Therefore, I could not further describe childless couples by the number of workers in the family, but information was available about families in general.

I found that the proportion of households with two or more workers increased significantly by $31.8 \%$ in the Northwest (see table VII). This became more clear when I compared that with the increase in the city overall, which was only $7.8 \%$ in the same period. The increase in the proportion of double income households in the Northwest was therefore 4.1 times higher than in the city.

TABLE VII

DOUBLE-INCOME FAMILIES ${ }^{\mathrm{a}}, 1980$ AND 1990

\begin{tabular}{lllcc}
\hline 1980 & 1990 & $\begin{array}{c}\text { change } \\
1980 \text { to } 1990\end{array}$ & $\begin{array}{c}\text { ratio of \% } \\
\text { change in the NW } \\
\text { to \% change in the } \\
\text { city }\end{array}$ \\
\hline City & $52.9 \%$ & $57.0 \%$ & $+7.8 \%$ & \\
\hline Northwest & $54.8 \%$ & $72.2 \%$ & $+31.8 \%$ & 4.077 \\
\hline
\end{tabular}

Source: Adapted from Census of Population and Housing, 1980, table P-10, and Census of Population of Housing, 1990, table 18.

$\mathrm{a}_{100 \%}=$ Families 
From this, I conclude that double-income households indeed had a prevailing presence in the revitalizing neighborhood also in the 1980s, but that in-moving families were more, rather than less, likely to have children at home. This corresponds to Gale's (1980) original expectations in his stage model of gentrification and not to Kerstein's (1990) more recent test of it.

\section{Age structure}

Gentrification is mainly attributed to young adults that move into the neighborhood (Gale 1980, 1984; Le Gates and Hartman 1981; Kerstein 1990). Gentrifiers are in their 20s and mid-30s. In many American cities, revitalization of city-core neighborhoods began in the late 1960s and early 1970s. Spain (1992) argued that this has demographic grounds (also Gale 1984, p. 80). It was in the early 1970s when the first part of the large post-war baby boom cohort ${ }^{3}$ entered the housing market and accelerated the demand for cheap city housing. Now, 20 years later, the same cohort is in its mid-20s to mid-40s with its largest group in the mid$30 \mathrm{~s}$ and mid-40s $\mathrm{s}^{4}$ Therefore, most of the residents who were young, single, and childless in the 70s are in the 80 s in the life-cycle stage where they are most likely to have a family and children, and families with children tend to choose suburban

${ }^{3}$ In the US, the term "baby boom" is referred to the period after World War II which is characterized by a sharp increase in the birthrate. "Baby boomers" are persons who are born between 1946 and 1965 (see e.g. Random House Webster's College Dictionary, 1992).

${ }^{4}$ The peak of the baby boom was the year 1957 . 
life instead of city life (Gans 1977; U.S. Department of Housing and Urban Development 1978). Now the "critical mass of [childless] households" (Spain 1992, p. 127) necessary for ongoing gentrification activity is not achieved by the succeeding age cohorts.

When I compared the census data for the median age (see table VIII), I found that on average the residents were slightly older in the Northwest compared to the city overall in both years, 1980 and 1990 . But the increase in median age was somewhat smaller in the Northwest, i.e. 2.4 years in the Northwest and 3.3 years in the city overall. In percentages, the median age in the Northwest increased by $7.3 \%$ and in the city by $10.6 \%$. The percentage increase in median age in the Northwest was therefore only $69 \%$ of that in the city. Thus, the gap in median age between the city overall and the Northwest neighborhood became smaller, so that the median age in the Northwest was higher by only 0.9 years in 1990 compared to 1.8 years in 1980.

I found basically the same when analyzing the median age of females. Only, the gap between the Northwest and the city diminished even more, so that the median age in the Northwest was higher by only 0.5 years in 1990 compared to 2.3 years in 1980 . The median age of women in the city overall therefore increased more than in the Northwest. 


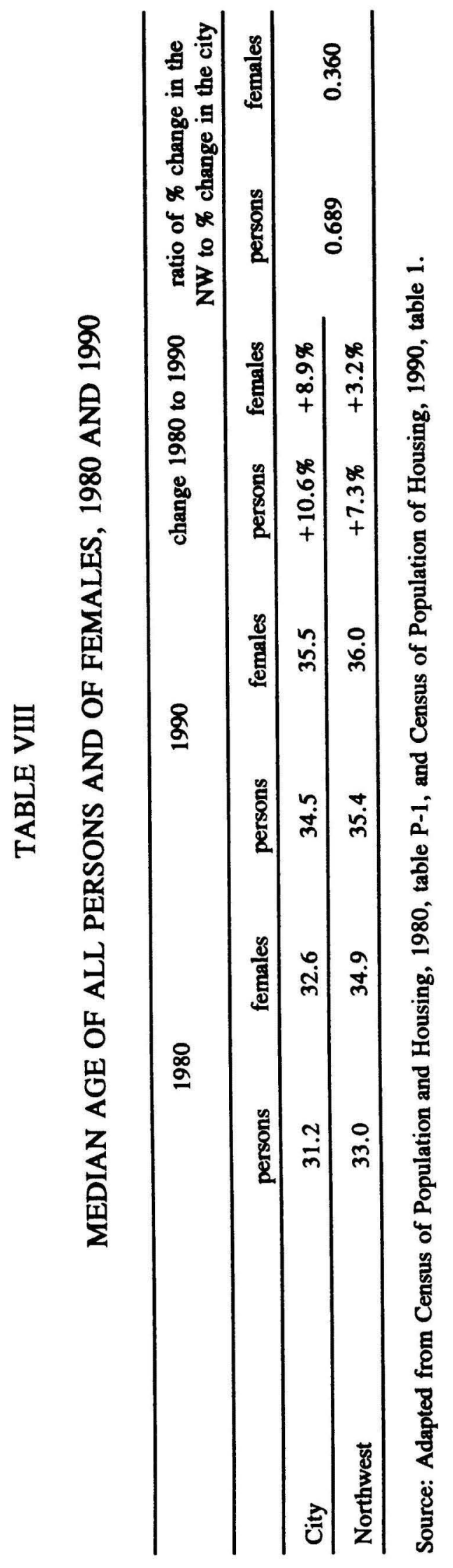


To get a more detailed picture of the shifts in the age distribution, I analyzed the complete age distribution in the Northwest neighborhood. I used an equilibrium model for the comparison, i.e. I assumed a balance of forces, so that the number of persons in an age cohort that leave the neighborhood is the same as new persons coming in over the time period of interest. Therefore I assumed "aging in place" which means that I expected the number of persons in one age cohort to be the same in 1980 and 10 years later in 1990.

With this method I can directly see shifts in the representation of different age cohorts in the Northwest neighborhood beyond what would be expected by simple aging in place. Further, I compared absolute numbers and not proportions, because the latter are not directly comparable over the years. For example, if there was a loss in the proportion of children, there was automatically a gain in the proportion of older age groups.

The comparison of the total number of persons living in the Northwest neighborhood shows that there were 88 fewer persons in 1990 than ten years before. This is a decrease of $2.3 \%$. The population in the city overall, though, increased by 70,364 persons, that is by $19.3 \%$. Gale (1984), too, found a decline in population in the gentrifying neighborhoods in his study for the period between 1970 and 1980 . While Gale (1984) expected "declines among children and older persons and growth among younger working-age adults" (p. 62) in the gentrifying area for the period of 1970 to 1980 , I specifically expected, in accordance with Spain's

\footnotetext{
${ }^{5}$ I adopted the idea of a "balance of forces" from Stinchcombe, 1968.
} 
hypothesis, a loss in the number of young adults and a gain in the number of middleaged persons, i.e. those who are 35 to 44 years old, due to the aged baby boom cohort.

Table IX shows that the city overall gained more people than expected in all age cohorts under age 65 . Only the age groups of those 65 years and older showed fewer persons than expected. This is no doubt due to a higher death rate in these ages. In the Northwest, by comparison, the age cohorts of the 10 to 14 year olds, 15 to 19 year olds, and 20 to 24 year olds in 1990 were the only cohorts where the actual number of persons was higher than expected. The city overall showed the higest increase also in exactly these three age groups, but the group of those 20 to 24 years old in the Northwest had an almost two and a half times higher increase in number than in the city, i.e. actually 3.8 persons more for every expected person in 1990. Instead, the cohort of those who are 35 to 44 years old decreased against the expectations by 308 persons, i.e. there were only 0.74 persons per expected member of the cohort in 1990.

I also found a substantially higher loss of old people in the Northwest compared to the city. The decrease of persons aged 65 to 74 years in the Northwest was $50 \%$ higher than in the city overall. Only the ratio for persons 85 years or older was about the same as it was in the city. 
TABLE IX

\section{RATIO OF ACTUAL TO EXPECTED NUMBERS OF PERSONS IN AGE COHORTS IN 1990 FOR THE CITY AND THE NORTHWEST ${ }^{2}$}

\begin{tabular}{|c|c|c|c|}
\hline $\begin{array}{c}\text { Age cohorts in } \\
1990^{b}\end{array}$ & $\begin{array}{c}\text { (1) } \\
\text { City } \\
\text { ratio of actual to } \\
\text { expected number }\end{array}$ & $\begin{array}{c}\text { (2) } \\
\text { Northwest } \\
\text { ratio of actual } \\
\text { to expected number }\end{array}$ & $\begin{array}{c}\text { Ratio of Northwest } \\
\text { to city } \\
(3)=(2) /(1)\end{array}$ \\
\hline 10 to 14 years & 1.02 & 1.00 & 0.98 \\
\hline 15 to 19 years & 1.22 & 1.55 & 1.27 \\
\hline 20 to 24 years & 1.57 & 3.80 & 2.42 \\
\hline 25 to 34 years & 1.26 & 1.83 & 1.45 \\
\hline 35 to 44 years & 1.01 & 0.74 & 0.73 \\
\hline 45 to 54 years & 1.14 & 0.83 & 0.73 \\
\hline 55 to 64 years & 1.06 & 0.67 & 0.63 \\
\hline 65 to 74 years & 0.92 & 0.46 & 0.50 \\
\hline 75 to 84 years & 0.70 & 0.49 & 0.70 \\
\hline 85 years and over & 0.31 & 0.33 & 1.06 \\
\hline
\end{tabular}

Source: Adapted from Census of Population and Housing, 1980, table P-1, and Census of Population and Housing, 1990, table 1.

a For tables showing the actual and expected numbers in 1980 and 1990 for the city and the Northwest refer to Appendix A, table XXIV and XXV.

b The age cohorts of "under 5 years" and " 5 to 9 years" are omitted in this table because there are no expectations for these age groups. Children at that age in 1990 were not born yet in 1980 which is the base year to derive from the expectations for 1990.

I found the same pattern for women in the Northwest. The ratio of actual to expected numbers of females aged 20 to 24 was even higher than for all persons, i.e. there were 4.13 women for every expected woman in 1990 . The ratio for those 35 to 44 years old was slightly higher than for all persons, i.e. 0.81 women for every 
expected woman in 1990 (refer to Appendix A, table XXV).

The findings show that the neighborhood is still very attractive to young persons, especially in the age groupd of those 20 to 24 years old, and not to older persons. This does not speak for a slowing down of the gentrification activity. Therefore, Spain's hypothesis was not supported, instead Gale's findings for the period of 1970 to 1980 were replicated. This suggests that the position that detects demographic shifts in the population overall as an explanation of gentrification cannot be upheld for the case of the Northwest.

\section{$\underline{\text { Gender }}$}

Several studies see women especially playing a role in the gentrification process (Beauregard 1986; Smith 1987; Mills 1988; Rose 1988; Warde 1991). The reasoning is parallel to the demographic argument that places the baby boomers on the demand side of gentrification. Spain (1992) stated, "Due to changes in the occupational structure and the entry of women into more lucrative careers, women are increasingly among the group of people fueling demand for gentrified housing" (p.128). On the other hand, women are more likely to be poor and, thus, prone to be displaced.

Specifically, studies report that single, working women and also single, young mothers prefer to live in the city instead of the suburb (Rose 1989) in order to be closer to work, child and health care, schools, shopping, and other services.

The analysis of the census data showed that while the proportion of women 
in the Northwest increased by $1.8 \%$, it decreased by $1.3 \%$ in the city overall. Moreover, the proportion of single women in the Northwest increased by $18.5 \%$ compared to an increase of $3.5 \%$ in the city. Also, the proportion of single mothers ${ }^{6}$ clearly increased at a higher rate in the Northwest than in the city overall, i.e. it increased by $6.7 \%$ in the Northwest while it decreased by $4.8 \%$ in the city (table X).

The same was true for the proportion of females in the labor force (table XI). It increased by $17.0 \%$ in the Northwest compared to $11.3 \%$ in the city. This was a 1.5 times faster increase in the Northwest. Further, the proportion of unemployed women in the Northwest decreased dramatically. It dropped by $47.7 \%$. In the city overall, the proportion of unemployed women declined by only $1.7 \%$. These findings are entirely consistent with the suggestions from the literature which sees women as gentrifiers.

Unfortunately, the census data does not provide income specified for women. Therefore, I used data for female headed households below the poverty level to examine the hypothesis that women are more likely to be displacees than among the gentrifiers. In general, the proportion of all persons below the poverty level decreased by $10.4 \%$ in the Northwest and increased by $12.3 \%$ in the city overall.

${ }^{6}$ Single mothers are described by the census as "female householder, no husband present with own children under 18." 

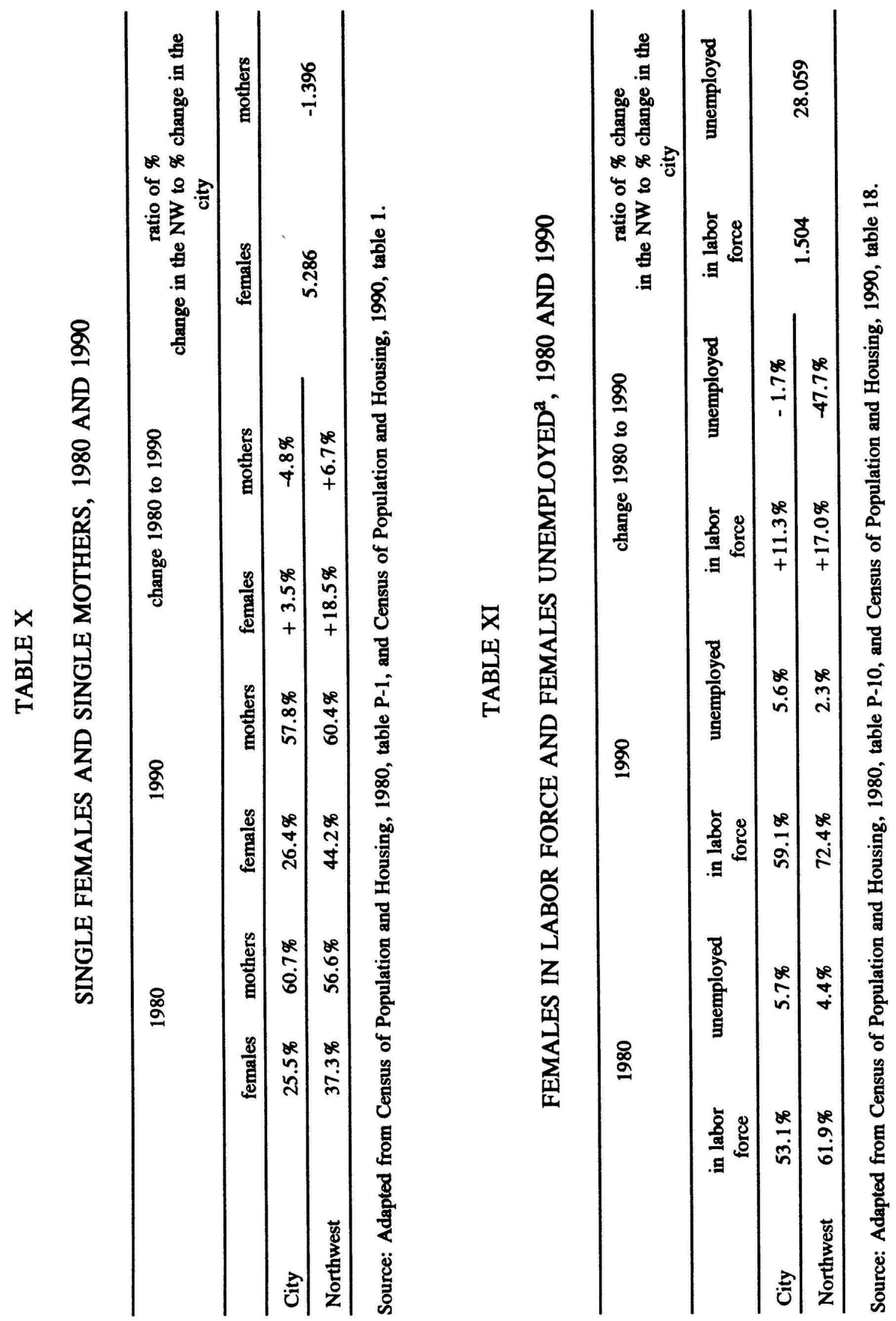
When I looked at the proportion of single mothers below the poverty level, I find that it increased by $9.9 \%$ in the city overall, but it decreased by $100 \%$ in the Northwest, i.e. the census did not report any female householder families below the poverty level in the Northwest in 1990 compared to $18.4 \%$ in 1980 (table XII). This indeed suggests that poor women are disproportionately among displaced persons. But the results above also imply that the neighborhood is very attractive to women in general and specifically to single, working women and single mothers. While it is not possible to crosstabulate income by gender, I must conclude from my findings that the female gentrifiers are women in higher income classes, who can afford to live in the neighborhood while women in lower income calsses are being displaced. When Smith (1987) compared women's incomes for 1960, 1973, and 1983, he found that "the relative increase in the number of upwardly mobile women is matched by a compensatory drop in the wealth of women lower down in the income scale" (p.157). This parallels my conclusion.

TABLE XII

FEMALE HOUSEHOLDERS, NO HUSBAND PRESENT BELOW POVERTY LEVEL, 1980 AND 1990

\begin{tabular}{lcccc}
\hline & 1980 & 1990 & $\begin{array}{c}\text { change } \\
1980 \text { to } 1990\end{array}$ & $\begin{array}{c}\text { ratio of \% change in the NW to } \\
\text { \% change in the city }\end{array}$ \\
\hline City & $25.2 \%$ & $27.7 \%$ & $+9.9 \%$ & \\
\hline Northwest & $18.4 \%$ & 0 & $-100.0 \%$ & -10.101 \\
\hline
\end{tabular}

Source: Adapted from Census of Population and Housing, 1980, table P-11, and Census of Population and Housing, 1990, table 19. 


\section{SHIFTS IN ECOLOGICAL PATTERNS}

\section{Geographic mobility}

One interesting characteristic of gentrifiers that is mentioned by several studies is the in-movers prior residential location. Many studies from the late 1970s give evidence that the hypothesis of a "back-to-the-city" movement has to be rejected. Instead, they found that most of the residents that are moving into the revitalizing area did not move from the suburbs but from within the city or even the same neighborhood (Gale 1976; Pattison 1977; Laska and Spain 1979; LeGates and Hartman 1981). Gale (1984) concluded that gentrifying neighborhoods especially attract "newcomers to the city" (p. 79) that moved from a different part of the country or from abroad.

These findings are described for the 1970s. But will I find the same situation for the 1980s? The analysis of the census data showed the same pattern as for the 1970s. While the Northwest had lower proportions of persons five years or older who lived in the same house five years ago when compared to the city in both 1980 and 1990, it nevertheless had a higher increase of this proportion. The city overall experienced a slight decrease of $2.1 \%$ of persons who lived in the same house five years ago, while the Northwest had an increase of $16.6 \%$. This is a 7.9 times higher change in the Northwest than in the city overall, indicative of increasing residential stability in the neighborhood during the 1980 s, but to a level still well below that of the city. 
In the city overall slightly over a fourth of the current residents moved to their present homes from within the central city in the past five years. In the Northwest this proportion was slightly higher at about a third of the residents, but it increased more slowly in the Northwest than in the city (table XIII). The proportion of residents in the Northwest that moved from within the central city increased by $2.3 \%$, while it increased by $8.1 \%$ in the city overall. The rest of the residents moved from somewhere else outside the city. The proportion of these residents was higher in the Northwest than in the city overall, but it declined at a higher rate. It decreased by $12 \%$ in the Northwest and by $4.4 \%$ in the city overall.

\section{TABLE XIII}

RESIDENCE FIVE YEARS AGO OF PERSONS 5 YEARS OR OLDER, 1980 AND 1990

\begin{tabular}{|c|c|c|c|c|}
\hline & 1980 & 1990 & $\begin{array}{c}\text { change } \\
1980 \text { to } 1990\end{array}$ & $\begin{array}{c}\text { ratio of } \% \\
\text { change in the NW to } \\
\% \text { change in the city }\end{array}$ \\
\hline \multicolumn{5}{|l|}{ Same house } \\
\hline City & $47.0 \%$ & $46.0 \%$ & $-2.1 \%$ & \multirow{2}{*}{-7.905} \\
\hline Northwest & $27.1 \%$ & $31.6 \%$ & $+16.6 \%$ & \\
\hline \multicolumn{5}{|c|}{ Different home in central city } \\
\hline City & $25.8 \%$ & $27.9 \%$ & $+8.1 \%$ & \multirow{2}{*}{0.284} \\
\hline Northwest & $30.5 \%$ & $31.2 \%$ & $+2.3 \%$ & \\
\hline \multicolumn{5}{|c|}{ Different home elsewhere } \\
\hline City & $27.3 \%$ & $26.1 \%$ & $-4.4 \%$ & \multirow{2}{*}{2.727} \\
\hline Northwest & $42.4 \%$ & $37.3 \%$ & $-12.0 \%$ & \\
\hline
\end{tabular}

Source: Adapted from Census of Population and Housing, 1980, table P-9, and Census of Population and Housing, 1990, table 17. 
In summary, increasingly more residents in the Northwest neighborhood had already lived in the same house five years ago, persons who moved from within the city increased only slightly, and fewer persons moved from outside the city. The development in the city overall instead shows a decline in residents who lived in the same house five years ago and a gain in persons who moved from within the city. The city attracted fewer new residents from outside the city as did the Northwest, but the decrease is smaller than in the Northwest.

This result demonstrates that Gale's finding of an increasing proportion of "newcomers" from outside the city in the gentrifying neighborhood is not found in the 1980s in the Northwest neighborhood in Portland, Oregon, and that the "back-tothe-city" hypothesis has to be rejected for this neighborhood, too. Instead, it seems that the high rate of in- and out-moving activity typical for gentrifying areas slowed down in the 1980s. This is consistent with my expectation that the Northwest entered a rather advanced stage of revitalization in the 1980 s where most of the housing stock was already renovated and housing prices had substantially increased. Therefore, the gentrification activity was gradually reduced, which diminished the high rate of demographic change in the beginning of the process and created a more stable situation.

\section{Proximity of home and workplace}

Another point in the explanation of genrification is that gentrifiers, who mainly are described as higher status white-collar workers such as professionals, 
managers and executives, want to live close to their downtown jobs (Spain 1992; Hamnett 1984; Beauregard 1986). It was also suggested that many of these people do not want to put up with long commuting distances and times anymore. Spain (1992) assumed that this is just "another type of conspicuous consumption" (p.129) of the yuppie lifestyle. "In other words, the ability to live close to one's work downtown is now a badge of financial success" (p.219). She, thus, proposed to test the hypothesis that residents of gentrifying areas live closer to their work and have shorter commuting times than other central city residents.

In fact, I found that persons living in the Northwest had shorter mean travel times to work than persons in the city overall. While the mean travel time to work increased by $3.0 \%$ in the city between 1980 and 1990 , it decreased by $9.5 \%$ in the Northwest (table XIV). This was a 3.2 times greater change in the Northwest than in the city overall, and in the opposite, but expected, direction.

\section{TABLE XIV}

MEAN TRAVEL TIME TO WORK IN MINUTES FOR WORKERS 16 YEARS AND OVER, 1980 AND 1990

\begin{tabular}{lllcl}
\hline 1980 & 1990 & $\begin{array}{c}\text { change } \\
1980 \text { to } 1990\end{array}$ & $\begin{array}{c}\text { ratio of \% } \\
\text { change in the NW } \\
\text { to \% change in the } \\
\text { city }\end{array}$ \\
\hline City & 19.7 & 20.3 & $+3.0 \%$ & \\
\hline Northwest & 17.9 & 16.2 & $-9.5 \%$ & -3.167 \\
\hline
\end{tabular}

Source: Adapted from Census of Population and Housing, 1980, table P-9, and Census of Population and Housing, 1990, table 17. 
To augment the analysis of the shorter-journey-to-work hypothesis I planned to include census data on place of work. But I decided not to use it, because the comparison of this data would be very problematic. First of all, the place of work data of the 1980 census relied on only about half of the sample, while the 1990 census data contained the total sample. Second, the categories of the place-of-work variable changed from 1980 to 1990 , and it was not clear which categories are comparable.

\section{Residential segregation}

A major theme in gentrification research is the issue of whites displacing blacks (Spain, Reid, and Long 1980; Spain 1981; Lee, Spain, and Umberson 1985). Several studies showed that a simple "black-to-white succession" (Gale 1984, p. 46) did not occur in gentrifying areas, but the situations were very different from city to city. It was found that racial segregation declined in many cities and that urban populations became more mixed (Massey and Denton 1987). Spain (1992) therefore suggested testing whether racial heterogeneity was encouraged in gentrifying neighborhoods or if racial segregation increased. Her expectation was that segregation declined.

Gale (1984) found in his comparison of five cities between 1970 and 1980 that "racial change in the revitalizing areas failed to consistently parallel that in the cities. Nor did racial change in these areas conform to the conventional view of net white gains and net minority losses" (pp.80-81). A major reason for this was that 
most gentrifying neighborhoods had about a 90 percent white population before gentrification started. Consequently, it was not possible to find a high decline of black population because of a high influx of white gentrifiers. Instead, Gale found a racially more mixed pattern.

Since Portland, too, had a about 85 percent white population and the Northwest neighborhood about a 95 percent white population, I expected to find a pattern of racial change comparable to the one Gale found.

Table XV shows that the racial composition of the Northwest did not change much. The proportion of white residents declined by $1 \%$ and the proportion of black residents doubled from $0.9 \%$ to $1.8 \%$ in the Northwest. The directions of these changes were consistent with racial changes generally found in urban places in recent times.

The surprising outcome was that the proportion of other races, especially Asian and Pacific Islander, remained exactly the same in the Northwest, while it increased by $30.5 \%$ in the city overall. I therefore conclude that the city of Portland became slightly more diversified in its racial composition, while the Northwest neighborhood showed almost the same pattern in 1990 as in 1980, with a $94 \%$ white, about a $2 \%$ black, and about $4 \%$ other race, with almost $3 \%$ Asian and Pacific Islander, population. Gentrification did therefore neither increase racial residential segregation, nor did it contribute to more heterogeneity. 
TABLE XV

RACE $^{\mathrm{a}}, 1980$ AND 1990

\begin{tabular}{|c|c|c|c|c|}
\hline & 1980 & 1990 & $\begin{array}{c}\text { change } \\
1980 \text { to } 1990\end{array}$ & $\begin{array}{l}\text { ratio of } \% \\
\text { change in the NW } \\
\text { to } \% \text { change in the } \\
\text { city }\end{array}$ \\
\hline \multicolumn{5}{|l|}{ White } \\
\hline City & $86.5 \%$ & $84.6 \%$ & $-2.2 \%$ & \multirow{2}{*}{0.455} \\
\hline Northwest & $95.2 \%$ & $94.3 \%$ & $-1.0 \%$ & \\
\hline \multicolumn{5}{|l|}{ Black } \\
\hline City & $7.6 \%$ & $7.7 \%$ & $+1.3 \%$ & \multirow{2}{*}{76.923} \\
\hline Northwest & $0.9 \%$ & $1.8 \%$ & $+100 \%$ & \\
\hline \multicolumn{5}{|l|}{ Other race ${ }^{b}$} \\
\hline City & $5.9 \%$ & $7.7 \%$ & $+30.5 \%$ & \multirow{2}{*}{0.000} \\
\hline Northwest & $3.9 \%$ & $3.9 \%$ & 0 & \\
\hline
\end{tabular}

Source: Adapted from Census of Population and Housing, 1980, table P-7, and Census of Population and Housing, 1990, table 8.
$a_{100 \%}=$ all persons
$\mathrm{b}$ other race $=$ American Indian, Eskimo, and Aleut, Asian and Pacific Islander, and other race. 


\section{CHAPTER V}

\section{CHANGES IN INTERACTIONAL AND SYMBOLIC FEATURES OF THE NORTHWEST NEIGHBORHOOD}

The perspective that is commonly missing in the gentrification literature is the perspective on changes in the quality of symbolic features of a gentrified community. This is why I did not only want to show the distinctive process of gentrification in the Northwest neighborhood as a kind of "case study", but to expand on the widely investigated issues in this field and to analyze, in an exploratory manner, changes in the symbolic community of the Northwest neighborhood.

\section{THEORETICAL MODELS AND EXPECTATIONS}

As was explained in chapter II, several factors influence neighborhood attachment, i.e. demographic characteristics of the residents, formal and informal interaction, social integration, and satisfaction with personal safety and the physical and social environment. A model can be outlined as in figure 2 . This model is not so much a causal model as an illustration of what factors are involved in neighborhood attachment. It is possible that the three factors in the center of figure 
2, satisfaction, social integration, and interaction, are interrelated, but it is not the goal of this thesis to find out about the causal relations in this model. What I am interested in is not the individual effect of each of the four factors on attachment and an analysis of the paths between the variables, but an exploration of changes that may have occurred in each of the variables in the attachment model during the last 15 years while gentrification proceeded and changed the Northwest neighborhood physically, commercially, and demographically.

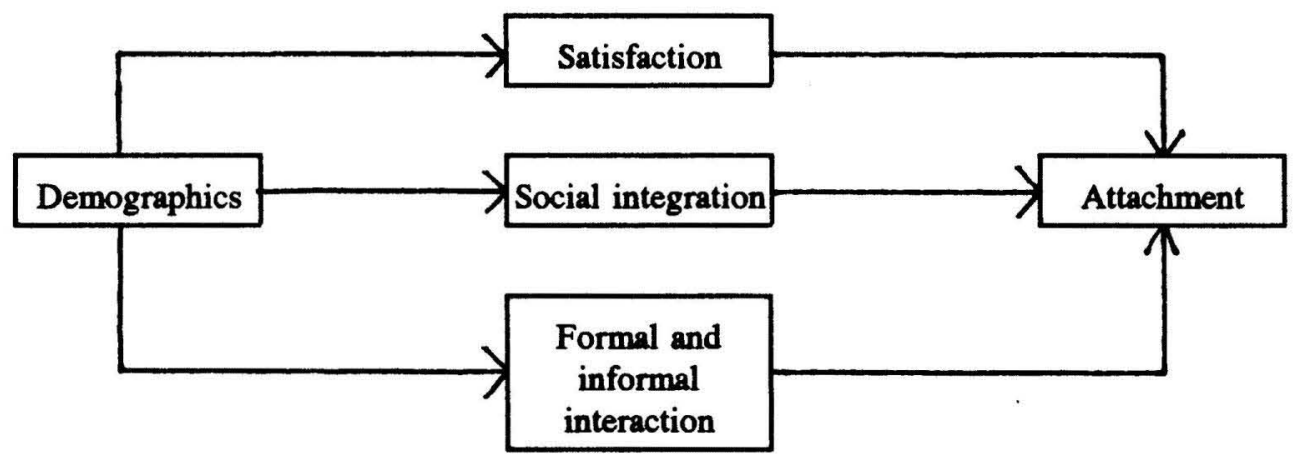

Figure 2. Factors influencing neighborhood attachment.

My expectation for an urban neighborhood in an advanced stage of gentrification, as is the Northwest neighborhood, is that it is symbolically more consistent with a "community of limited liability" than with an "urban village". Guest and Lee (1983b) found a "community of limited liability" particularly characterized by high housing values and high status residents who are satisfied with the physical and social environment rather than tied to the neighborhood by intimate 
social relations. A gentrified neighborhood seems to me accurately described in that way, i.e. as a "nice place to live." Thus, I expected for the Northwest neighborhood, in the most recent time period especially, higher satisfaction levels but less frequent and intense social contacts with neighbors and less strong bonds with the neighborhood.

\section{DATA AND MEASURES}

\section{Survey data}

Because attitudinal characteristics are not addressed in the census, to study changes in interactional and attitudinal characteristics of the Northwest neighborhood residents I used data of a survey conducted in 1978 and again in 1993 by Dr. Lee J. Haggerty and his students in survey research classes at Portland State University. Since the survey questionnaire was originally not created for my specific purposes, but for the examination of differential social contact in urban neighborhoods in Portland, Oregon (see Haggerty 1982), the survey data, as the census data, is secondary data in my research. Nevertheless, I participated in the revision of the survey instrument, the collection and the coding of the data in 1993. Therefore, I have an insight of how the re-study was designed and conducted, which gives me some helpful knowledge about the quality of the data.

The investigated area in the survey is consistent with the census tract 47 . Households were randomly selected within areally stratified housing clusters to 
assure an areally representative sample of households proportional to the total number of households in the area. Data exists for 106 respondents in 1978 and 116 respondents in 1993. The re-study in 1993 used the same instrument that was used in 1978. There were only some slight changes in the layout and some adjustments of categories to the present time, e.g. the income categories. The questionnaire measures frequency and extensiveness of contacts between neighbors, participation in and attachment to the neighborhood, and sociodemographic characteristics of the respondents. The survey was designed to include only adult females. Haggerty (1982) explains:

Because of well-documented sex differences in neighboring activities [...] [see Campbell and Lee, 1990; S.O.], only female respondents were utilized so as to eliminate sex as a plausible explanation for any observed differences in neighboring patterns (p. 362).

\section{Measures}

Referring to the model of neighborhood attachment, I created six index variables to measure total satisfaction, formal interaction, informal interaction, social integration, alienation, and attachment. The measure of total satisfaction is the sum of four score variables, i.e. a "personal-safety score", a "security-withcrime score", a "satisfaction score for the physical environment and neighborhood services", and a "neighborhood-attractiveness score" (for a detailed explanation of the score variables refer to appendix B). The measure of formal interaction contains the number of neighborhood organizations a respondent belonged to, the number of leadership positions taken in neighborhood organizations, whether time was 
volunteered for neighborhood events, and whether a respondent had ever worked for a charity fund in the neighborhood. The informal interaction measure includes a "neighboring-frequency score," a "neighboring-extensiveness score," and a "neighboring-intensiveness score." I created the social integration measure referring to the study of St. John et al. (1986) who used length of residence and number of friends that lived in the neighborhood as measures of social integration. The measure of alienation consists of alienation from neighbors and of alienation from people in general. Attachment is measured by answers to the question whether respondents planned to stay in the neighborhood, whether they would come back to visit their neighbors and whether they would keep in touch with their neighbors if they were to move away. For a more detailed explanation of the score and index variables refer to appendix B.

\section{FINDINGS}

\section{Demographic, interactional, and attitudinal profile of the neighborhood}

Before I talk about the results of the comparison of neighboring, satisfaction, and attachment measures in 1978 and 1993, I want to give a brief overview of the demographic composition of the survey sample of 1993 and a summary of the respondents' neighboring behavior and their attitudes toward their neighborhood.

About $60 \%$ or $3 / 5$ of the persons or families in the survey rented their homes or apartments. More than half of them (56.5\%) lived in the same house or apartment 
for one to five years. Almost half of the respondents (45\%) moved from within the city of Portland to their present home or had always lived in this neighborhood. More than $90 \%$ had at least some years of college or were college graduates and $56 \%$ had a completed college degree. Seventy-eight percent of the respondents worked full or part time, $2.8 \%$ were unemployed. The remainder kept the house, were retired, went to school, or had other occupations. Twenty-two percent had an annual family income of $\$ 50,000$ or more and about $1 / 4$ had an annual family income of less than $\$ 15,000$. The majority had an income of $\$ 15,000$ to $\$ 49,999$. The mean age of the respondents was 34.1 years which is lower than what the 1990 census reported (36.0 years for females, 35.4 years for all persons; see chapter IV). Four fifth of the respondents in the survey were under the age of 45 . The relatively young population is also reflected in the household composition. About half of the households were composed of "Young individuals," and more than 1/4 (28.2\%) are "Young couples" or "Young families" (see table XVI ). In summary, the surveyed respondents reproduced the basic demographic composition that was found for the Northwest neighborhood with 1990 census data very closely. 
TABLE XVI

\section{LIFE-CYCLE STAGES ${ }^{7}$ OF SURVEY RESPONDENTS IN THE NORTHWEST NEIGHBORHOOD, 1978 AND 1993}

\begin{tabular}{lcccc}
\hline Life-cycle stage & \multicolumn{2}{c}{1978} & \multicolumn{2}{c}{1993} \\
& $\mathrm{~N}$ & $\%$ & $\mathrm{~N}$ & $\%$ \\
\hline Young individuals & 39 & 40.6 & 53 & 48.2 \\
\hline Single parents & 22 & 22.9 & 4 & 3.6 \\
\hline Young couples & 10 & 10.4 & 18 & 16.4 \\
\hline Young families & 6 & 6.3 & 13 & 11.8 \\
\hline Old families & 0 & - & 1 & .9 \\
\hline Old couples & 8 & 8.3 & 11 & 10.0 \\
\hline Old individuals & 11 & 11.5 & 10 & 9.1 \\
\hline Total & 96 & 100 & 110 & 100 \\
\hline
\end{tabular}

In 1993, when asked about their neighboring behavior, 40 percent of the respondents said they knew between one and five neighbors by name. Nine percent did not know any of their neighbors by name. When they were asked about the source of their closest friends, 11 percent said that their neighbors were among their closest friends. $4 / 5$ of the respondents had no or only few friends living in the

${ }^{7}$ For the creation of the life-cycle stages, I used Haggerty's (1982) classification:

\begin{tabular}{lcccc}
\hline & \multicolumn{2}{c}{ Under age 45 } & \multicolumn{2}{c}{ Age 45 and over } \\
& Married & Not married & Married & Not married \\
\cline { 2 - 5 } Children at home & Young families & Single parents & Old families & Single Parents \\
No children at home & Young couples & Young individuals & Old couples & Old individuals \\
\hline
\end{tabular}


neighborhood.

More than a third (34.5\%) said they wave to their neighbors every day. About $2 / 5$ chatted outside with their neighbors daily or several times $a$ week and more than half of them (54\%) chatted with one to four neighbors. Only about $1 / 6$ of the respondents visited with their neighbors inside their or their neighbors' homes daily or several times a week. Two thirds hardly ever visited their neighbors or were visited by them. More than half (53\%) of the residents visited with one to four neighbors inside the house. Only 10 percent of the respondents said that they had long personal discussions with their neighbors daily or several times a week. 46 percent had personal talks with one to four neighbors. Sixty-eight percent said that they hardly ever had long personal discussions with their neighbors. When they were asked to what extent they rely on their neighbors to discuss certain topics, about half or a slight majority said they discuss personal problems (59\%), home maintenance (53\%), personal joys and problems (51\%), politics or current events $(50 \%)$, and shopping (45\%) frequently or occasionally. Asked about a general assessment of their neighbors, the vast majority of the respondents said their neighbors try to be helpful (85\%), their neighbors would be fair and would not take advantage of them (91\%), and they can trust them (85\%).

The residents were also asked about their participation in neighborhood events and organizations. Two thirds of them replied that they did not belong to any club or organization in the neighborhood. Of the respondents who belonged to a neighborhood organization, seventeen percent had held a leadership position. About 
a third of the residents in the survey had volunteered time to neighborhood events and about $1 / 5$ had worked for a charity fund in the neighborhood.

The majority of the respondents in 1993 felt very safe or safe walking on the street in daylight $(98 \%)$, walking on the street at night $(61 \%)$, walking from their car to their house at night (83\%), and visiting the nearest park (68\%). Most of them felt very secure or secure from certain types of crime in their neighborhood, specifically from assault (65\%), harassment $(61 \%)$, robbery (59\%), burglary (54\%) and vandalism $(52 \%)$.

Most of the respondents said that they were satisfied or very satisfied with certain aspects of the neighborhood environment and services, specifically they were satisfied or very satisfied with quality of housing (89\%), neighborhood upkeep (83\%), parks (80\%), public transportation $(77 \%)$, trust among neighbors $(77 \%)$, shopping facilities $(72 \%)$, personal security $(68 \%)$, animal control $(65 \%)$, fire protection (63\%), and police protection (61\%). Fewer persons were satisfied or very satisfied with the noise level (49\%), street lighting (49\%), parking spaces (37\%), and traffic flow (23\%; 37\% neutral). More than half of the respondents were neutral about neighborhood schools (59\%) and property taxes (53\%). Most of the respondents listed between one and three most attractive features of their neighborhood (85\%) and between one and three least attractive (80\%).

The answers to questions about attachment to the neighborhood showed that 81 percent planned to stay in the neighborhood for the foreseeable future, 58 percent would keep in touch with their present neighbors if they were to move out, and 58 
percent would return to visit their present neighbors.

\section{Analysis}

All persons. T-tests with the index variables that I created resulted in few statistically significant $(p<.05)$ differences between the means in 1978 and 1993. None of the index variables had significantly different means, except the informal interaction variable which had a lower mean in 1993 than in $1978(p=.038)$. This must be attributed to the lower mean scores of its component parts of neighboring frequency $(p=.01)$ and neighboring extensiveness $(p=.023)$. Neither the attachment mean score nor the alienation, social integration, formal interaction, or total satisfaction mean scores differed on a significant level. The security-from-crime mean score was the only component of the total satisfaction score that was significantly different in 1993 compared to $1978(p=.002)$, i.e. residents on average felt more secure from crime in 1993. In summary, this suggests that residents of the Northwest neighborhood in 1993 were not more (or less) attached, socially integrated, alienated, or satisfied than 15 years ago, nor did they interact more (or less) on a formal basis, but they felt in general more secure from crime in the neighborhood than before and they had on average less informal contacts with their neighbors.

However, the measures so far had the disadvantage that they summarized several individual measures which may have evened out positive and negative changes in the individual components of the composite variables, so that it resulted 
in only these few significant differences. Therefore, I tested all 52 individual variables, which I used to create the index variables, separately on significant differences in their means between 1978 and 1993 . Table XVII shows only measures that were found to have statistically significant differences in means on at least the 95\%-confidence level.

Except for the means on numbers of friends, neighbors, etc., the means in the table are means on coded Likert-scale items and not on actual quantities. However, the means can be compared for the two years in order to find the direction of change, since all the variables are coded so that high values refer to high safety, security, satisfaction, frequency, intensity, attachment, etc.

Although residents in 1993 are not found to be more (or less) attached than 15 years ago, they are more satisfied with certain aspects of the physical environment, such as housing and neighborhood upkeep, and with security in the neighborhood in general. They feel safer to walk on the street at night and feel more secure from burglary, assault, and robbery, but they are less satisfied with some neighborhood services, such as street lighting and public transportation. Residents in 1992 list fewer unattractive features of the neighborhood than residents in 1978. The neighboring behavior in the neighborhood changed in so far as residents have fewer friends living in the area, visit with fewer neighbors and less frequently in each other's homes, chat less often outside and discuss politics less frequently with their neighbors. 


\section{TABLE XVII}

STATISTICALLY SIGNIFICANT DIFFERENCES BETWEEN 1978 AND 1993 IN MEANS OF NEIGHBORING, SATISFACTION, AND ATTACHMENT MEASURES, ALL PERSONS

\begin{tabular}{|c|c|c|c|c|}
\hline \multirow[t]{2}{*}{ Measure } & \multicolumn{2}{|c|}{ Mean on measure } & \multicolumn{2}{|c|}{ Direction Significance } \\
\hline & $1978(N)$ & $1993(\mathrm{~N})$ & $\begin{array}{c}\text { of } \\
\text { change }\end{array}$ & $\begin{array}{c}\text { of } \\
\text { difference }^{\mathrm{a}}\end{array}$ \\
\hline \# of friends in neighborhood & $1.33(105)$ & $.92(115)$ & - & $.001^{-1}$ \\
\hline Frequency of chats with neighbors outside & $2.51(105)$ & $2.22(113)$ & - & $.040^{*}$ \\
\hline Frequency of visits with neighbors inside homes & $1.92(105)$ & $1.54(112)$ & - & $.003^{-*}$ \\
\hline$\#$ of neighbors visited inside homes & $1.99(105)$ & $1.33(113)$ & - & $.001^{* *}$ \\
\hline $\begin{array}{l}\text { Frequency of discussions about politics with } \\
\text { neighbors }\end{array}$ & $2.68(101)$ & $2.40(116)$ & - & $.038^{*}$ \\
\hline Safety walking on the street at night & $2.15(105)$ & $2.60(112)$ & + & $.000^{-1}$ \\
\hline Security from burglary & $2.25(104)$ & $2.53(116)$ & + & $.005^{* *}$ \\
\hline Security from assault & $2.23(105)$ & $2.64(114)$ & + & $.000^{-}$ \\
\hline Security from robbery & $2.32(104)$ & $2.57(116)$ & + & $.006^{-*}$ \\
\hline Satisfaction with housing & $3.78(105)$ & $4.22(114)$ & + & $.000^{-\infty}$ \\
\hline Satisfaction with upkeep & $3.45(105)$ & $3.98(115)$ & + & $.000^{-1 *}$ \\
\hline Satisfaction with animal control & $3.03(105)$ & $3.66(116)$ & + & .000 \\
\hline Satisfaction with security & $3.23(104)$ & $3.52(116)$ & + & $.032^{*}$ \\
\hline Satisfaction with street lighting & $3.64(103)$ & $3.28(116)$ & - & .006 \\
\hline Satisfaction with public transportation & $4.49(105)$ & $4.00(115)$ & - & $.000^{-}$ \\
\hline $\begin{array}{l}\text { \# of unattractive neighborhood features } \\
\text { listed }\end{array}$ & $1.68(106)$ & $1.46(112)$ & - & $.038^{*}$ \\
\hline
\end{tabular}

Note: ${ }^{a}$ Based on t-test using separate variance estimation, 2-tailed tests. ${ }^{*} \mathrm{p}<.05 ;{ }^{-*} \mathrm{p}<.01$; $\mathrm{p}<.001$.

In summary, surprisingly few aspects of the symbolic and interactional characteristics of the Northwest neighborhood changed significantly in the last 15 years, although the neighborhood was transformed physically and demographically 
by gentrification activity. However, the particular aspects that did change support the expectations of more satisfied, but less interacting residents and a perception of the neighborhood as a nicer and safer place.

Life-cycle stages. Up to this point, I have not analyzed specific life-cycle or socio-economic status groups, but I wanted to include tests for changes in satisfaction, attachment, and neighboring for specific status groups and the life-cycle stages I described earlier, for two reasons: first, as described in chapter II, life-cycle and socio-economic status have been found to influence neighboring behavior, attachment to, and satisfaction with the neighborhood in certain ways, and second, since the neighborhood was demographically changed (as presented in chapter IV), I suspect that certain groups have different levels of satisfaction, attachment, or neighboring.

As I stated earlier in this chapter, the gentrification literature pays no attention to resulting changes in interactional and symbolic characteristics of the community. Thus, I had no indications from the literature for expectations, especially for neighboring behavior. This is why the following analysis was basically exploratory. Yet, I expected older persons to be more marginal in the most recent time than in the year of the first survey, since particularly young persons in early life-cycle stages were attracted to the Northwest neighborhood (see also chapter IV) and represented over $2 / 3$ of the households in 1993. From the neighboring and attachment literature I expected lower attachment and satisfaction of older people, since their "critical mass" has declined greatly. I expected that younger gentrifiers 
will more likely exhibit interaction and attachment patterns consistent with the "community of limited liability" example.

Because the t-tests I conducted for the analysis of the different life-cycle stages resulted in low N's in the subgroups of the two compared years, the outcome has to be interpreted with caution. The t-tests showed (see tables XVIII, XIX, and $\mathrm{XX)}$ that young individuals and couples had somewhat smaller neighbor networks in 1993 compared to 1978 , since, in 1993, they knew fewer neighbors by name, fewer friends lived in the neighborhood, and they chatted, visited, and had personal discussions with fewer neighbors. They also neighbored somewhat less frequently, since they chatted less frequently outside, visited less frequently inside homes, less frequently had long personal discussions, and discussed politics less frequently. Yet, young families discussed shopping more often.

Somewhat fewer young individuals participated formally in the neighborhood in 1993 than 15 years before, as fewer of them volunteered time to a neighborhood organization. Young individuals and couples felt more safe walking at night on neighborhood streets and going from the car to the house at night. Especially young individuals felt more secure from burglary, assault, robbery, and harassment. The satisfaction with the neighborhood features differed for the life-cycle stages. Young individuals felt more satisfied with the neighborhood upkeep and animal control, but less satisfied with public transportation and neighborhood parks. Young couples are more satisfied with security. Young families are less satisfied with the noise level and traffic in the neighborhood. 
TABLE XVIII

STATISTICALLY SIGNIFICANT DIFFERENCES BETWEEN 1978 AND 1993 IN MEANS OF NEIGHBORING, SATISFACTION, AND ATTACHMENT MEASURES, YOUNG INDIVIDUALS

\begin{tabular}{|c|c|c|c|c|}
\hline \multirow[t]{2}{*}{ Measure } & \multicolumn{2}{|c|}{ Mean on measure } & \multirow{2}{*}{$\begin{array}{l}\text { Direction } \\
\text { of change }\end{array}$} & \multirow{2}{*}{$\begin{array}{c}\text { Significance }^{8} \\
\text { of } \\
\text { difference }\end{array}$} \\
\hline & $1978(N)$ & $1993(\mathrm{~N})$ & & \\
\hline Frequency of chats with neighbors outside & $2.31(39)$ & $1.73(52)$ & - & $.009^{-*}$ \\
\hline Frequency of visits with neighbors inside homes & $1.92(39)$ & $1.35(52)$ & - & $.006 *$ \\
\hline $\begin{array}{l}\text { Frequency of long personal discussions with } \\
\text { neighbors }\end{array}$ & $1.69(39)$ & $1.29(51)$ & - & $.018^{*}$ \\
\hline $\begin{array}{l}\text { Frequency of discussions about politics with } \\
\text { neighbors }\end{array}$ & $2.59(37)$ & $2.04(53)$ & - & $.010^{*}$ \\
\hline \# of neighbors known by name & $3.69(39)$ & $2.51(51)$ & - & $.001^{* *}$ \\
\hline \# of neighbors chatted with outside & $2.51(39)$ & $1.85(52)$ & - & $.036^{*}$ \\
\hline \# of neighbors visited inside homes & $1.85(39)$ & $0.83(52)$ & - & $.000^{-\infty}$ \\
\hline \# of neighbors having personal discussions with & $2.59(39)$ & $0.77(52)$ & - & $.002^{* * *}$ \\
\hline \# of friends in the neighborhood & $1.31(39)$ & $0.74(53)$ & - & $.002^{* * *}$ \\
\hline Safety walking on the street at night & $3.13(39)$ & $3.76(49)$ & + & $.000^{-\infty}$ \\
\hline Security from burglary & $2.29(38)$ & $2.64(53)$ & + & $.009^{-*}$ \\
\hline Security from assault & $2.08(39)$ & $2.67(52)$ & + & $.000^{-00}$ \\
\hline Security from robbery & $2.34(38)$ & $2.62(53)$ & + & $.046^{*}$ \\
\hline Security from harassment & $2.26(38)$ & $2.55(53)$ & + & $.048^{*}$ \\
\hline Satisfaction with upkeep & $3.36(39)$ & $3.88(52)$ & + & $.008^{-*}$ \\
\hline Satisfaction with animal control & $3.15(39)$ & $3.74(53)$ & + & $.005^{-}$ \\
\hline Satisfaction with public transportation & $4.54(39)$ & $3.91(53)$ & - & $.000^{-}$ \\
\hline Satisfaction with neighborhood parks & $4.28(39)$ & $3.92(53)$ & - & $.032^{*}$ \\
\hline$\#$ of unattractive neighborhood features listed & $1.87(39)$ & $1.37(53)$ & - & $.000^{-}$ \\
\hline Did volunteer time to neighborhood organization & $0.32(38)$ & $0.13(53)$ & - & $.045^{*}$ \\
\hline Would keep in touch if moved away & $0.66(38)$ & $0.43(51)$ & - & $.034^{*}$ \\
\hline Would return to visit if moved away & $0.66(38)$ & $0.42(53)$ & - & $.022^{*}$ \\
\hline
\end{tabular}

${ }^{\mathrm{a}}$ Based on t-test using separate variance estimation, 2-tailed tests; ${ }^{*} \mathrm{p}<.05 ;{ }^{-} \mathrm{p}<.01 ;{ }^{-} \mathrm{p}<.001$. 
TABLE XIX

STATISTICALLY SIGNIFICANT DIFFERENCES BETWEEN 1978 AND 1993 IN MEANS OF NEIGHBORING, SATISFACTION, AND ATTACHMENT MEASURES, YOUNG COUPLES

\begin{tabular}{|c|c|c|c|c|}
\hline \multirow[t]{2}{*}{ Measure } & \multicolumn{2}{|c|}{ Mean on measure } & \multirow{2}{*}{$\begin{array}{l}\text { Direction } \\
\text { of change }\end{array}$} & \multirow{2}{*}{$\begin{array}{c}\text { Significance }^{\mathrm{a}} \\
\text { of } \\
\text { difference }\end{array}$} \\
\hline & $1978(N)$ & $1993(\mathrm{~N})$ & & \\
\hline Frequency of visits with neighbors inside homes & $2.33(9)$ & $1.35(17)$ & - & $.033^{*}$ \\
\hline \# of neighbors visited inside homes & $2.30(10)$ & $1.22(18)$ & - & $.048^{*}$ \\
\hline Safety walking on the street at night & $2.70(10)$ & $3.67(18)$ & + & $.002^{-m}$ \\
\hline Safety going from car to house at night & $3.50(10)$ & $4.22(18)$ & + & $.004^{* *}$ \\
\hline Security from assault & $2.00(10)$ & $2.78(18)$ & + & $.033^{*}$ \\
\hline Satisfaction with security & $2.80(9)$ & $3.72(18)$ & + & $.006^{*}$ \\
\hline
\end{tabular}

a Based on t-test using separate variance estimation, 2-tailed tests; ${ }^{*} \mathrm{p}<.05 ;{ }^{*} \mathrm{p}<.01$

\section{TABLE XX}

STATISTICALLY SIGNIFICANT DIFFERENCES BETWEEN 1978 AND 1993 IN MEANS OF NEIGHBORING, SATISFACTION, AND ATTACHMENT MEASURES, YOUNG FAMILIES

\begin{tabular}{|c|c|c|c|c|}
\hline \multirow[t]{2}{*}{ Measure } & \multicolumn{2}{|c|}{ Mean on measure } & \multirow{2}{*}{$\begin{array}{l}\text { Direction } \\
\text { of change }\end{array}$} & \multirow{2}{*}{$\begin{array}{c}\text { Significance }^{\mathrm{a}} \\
\text { of } \\
\text { difference }\end{array}$} \\
\hline & $1978(N)$ & $1993(\mathrm{~N})$ & & \\
\hline $\begin{array}{l}\text { Frequency of discussions about shopping with } \\
\text { neighbors }\end{array}$ & $1.80(5)$ & $3.15(13)$ & + & $.049^{*}$ \\
\hline Satisfaction with traffic & $3.80(5)$ & $3.08(13)$ & - & $.046^{*}$ \\
\hline Satisfaction with noise level & $4.20(5)$ & 3.23 (13) & - & $.013^{*}$ \\
\hline
\end{tabular}

a Based on t-test using separate variance estimation, 2-tailed tests; ${ }^{*} \mathrm{p}<.05$. 
Particularly young individuals found the neighborhood more attractive, as they did not list fewer attractive neighborhood features but did list fewer unattractive neighborhood features.

The attachment to the neighborhood did not change for most of the young life-cycle stages, except that young individuals were less attached in 1993 compared to 1978 , and fewer of them would keep in touch with their neighbors and return to visit if they moved away.

Single parents differed from the other household types as they felt less secure from assault, harassment, and vandalism, but this result is not very reliable, because there were only four single parents in 1993 (table XXI).

TABLE XXI

STATISTICALLY SIGNIFICANT DIFFERENCES BETWEEN 1978 AND 1993 IN MEANS OF NEIGHBORING, SATISFACTION, AND ATTACHMENT MEASURES, SINGLE PARENTS

\begin{tabular}{|c|c|c|c|c|}
\hline \multirow[t]{2}{*}{ Measure } & \multicolumn{2}{|c|}{ Mean on measure } & \multirow{2}{*}{$\begin{array}{l}\text { Direction } \\
\text { of change }\end{array}$} & \multirow{2}{*}{$\begin{array}{c}\text { Significance }^{\mathrm{a}} \\
\text { of } \\
\text { difference }\end{array}$} \\
\hline & $1978(\mathrm{~N})$ & $1993(\mathrm{~N})$ & & \\
\hline Frequency of visits with neighbors inside homes & $2.05(22)$ & $1.25(4)$ & - & $.041^{*}$ \\
\hline \# of friends in the neighborhood & $1.64(22)$ & $0.50(4)$ & - & $.018^{*}$ \\
\hline Security from vandalism & $2.59(22)$ & $1.75(4)$ & - & $.031^{*}$ \\
\hline Security from assault & $2.55(22)$ & $2.00(4)$ & - & $.007^{-1}$ \\
\hline Security from harassment & $2.64(22)$ & $2.00(4)$ & - & $.001^{-}$ \\
\hline Satisfaction with noise level & $3.18(22)$ & $2.25(4)$ & - & $.025^{*}$ \\
\hline Satisfaction with fire protection & $3.86(22)$ & $2.75(4)$ & - & $.009^{-1}$ \\
\hline \# of unattractive neighborhood features listed & $1.64(22)$ & $0.50(4)$ & - & $.018^{*}$ \\
\hline
\end{tabular}


Old individuals and couples knew, in contrast to young individuals, more neighbors by name in 1993 than 15 years before (see table XXII). Only the old couples were more likely to discuss personal joys and home maintenance with neighbors more frequently. As did young persons, old individuals felt more safe walking at night in the neighborhood, felt more secure from assault and robbery, and were more satisfied with the neighborhood upkeep, animal control, and with housing and trust among neighbors.

\section{TABLE XXII}

STATISTICALLY SIGNIFICANT DIFFERENCES BETWEEN 1978 AND 1993 IN MEANS OF NEIGHBORING, SATISFACTION, AND ATTACHMENT MEASURES, OLD INDIVIDUALS

\begin{tabular}{|c|c|c|c|c|}
\hline \multirow[t]{2}{*}{ Measure } & \multicolumn{2}{|c|}{ Mean on measure } & \multirow{2}{*}{$\begin{array}{l}\text { Direction } \\
\text { of change }\end{array}$} & \multirow{2}{*}{$\begin{array}{c}\text { Significance }^{\mathrm{a}} \\
\text { of } \\
\text { difference }\end{array}$} \\
\hline & $1978(N)$ & $1993(\mathrm{~N})$ & & \\
\hline \# of neighbors known by name & $3.64(11)$ & $4.78(9)$ & + & $.043^{*}$ \\
\hline $\begin{array}{l}\text { Worked for charity fund drive in the } \\
\text { neighborhood }\end{array}$ & $0.10(10)$ & $0.56(9)$ & + & $.042^{*}$ \\
\hline Safety walking on the street at night & $2.82(11)$ & $3.70(10)$ & + & $.048^{*}$ \\
\hline Safety walking from car to house at night & $3.50(10)$ & $4.50(10)$ & + & $.027^{*}$ \\
\hline Security from assault & $2.18(11)$ & $2.78(9)$ & + & $.020^{*}$ \\
\hline Security from robbery & $2.09(11)$ & $2.70(10)$ & + & $.004^{* * *}$ \\
\hline Satisfaction with housing & $3.55(11)$ & $4.78(9)$ & + & $.001^{-1}$ \\
\hline Satisfaction with upkeep & $3.18(11)$ & $4.50(10)$ & + & $.001^{-1-}$ \\
\hline Satisfaction with noise level & $3.00(11)$ & $4.10(10)$ & + & $.015^{*}$ \\
\hline Satisfaction with trust among neighbors & $3.91(11)$ & $4.50(10)$ & + & $.020^{*}$ \\
\hline Would return to visit if moved away & $0.30(10)$ & $0.80(10)$ & + & $.024^{*}$ \\
\hline
\end{tabular}

a Based on t-test using separate variance estimation, 2-tailed tests; ${ }^{*} \mathrm{p}<.05 ;{ }^{* *} \mathrm{p}<.01$. 
However, in contrast to young families, old individuals were more satisfied in 1993 with the noise level in the neighborhood. Also, more of them participated formally in the community, as more old individuals had worked for a charity fund drive in the neighborhood. In contrast to young individuals, old individuals were more attached to the neighborhood, as more of them would return to visit if they were to move away.

TABLE XXIII

STATISTICALLY SIGNIFICANT DIFFERENCES BETWEEN 1978 AND 1993 IN MEANS OF NEIGHBORING, SATISFACTION, AND ATTACHMENT MEASURES, OLD COUPLES

\begin{tabular}{|c|c|c|c|c|}
\hline \multirow[t]{2}{*}{ Measure } & \multicolumn{2}{|c|}{ Mean on measure } & \multirow{2}{*}{$\begin{array}{l}\text { Direction } \\
\text { of change }\end{array}$} & \multirow{2}{*}{$\begin{array}{c}\text { Significance }^{a} \\
\text { of } \\
\text { difference }\end{array}$} \\
\hline & $1978(N)$ & $1993(\mathrm{~N})$ & & \\
\hline $\begin{array}{l}\text { Frequency of discussions about personal joys } \\
\text { with neighbors }\end{array}$ & $1.86(7)$ & $2.91(11)$ & + & $.015^{*}$ \\
\hline $\begin{array}{l}\text { Frequency of discussions about home } \\
\text { maintenance with neighbors }\end{array}$ & $2.29(7)$ & $3.27(11)$ & + & $.038^{*}$ \\
\hline Satisfaction with animal control & $2.50(8)$ & $3.73(11)$ & + & $.030^{*}$ \\
\hline
\end{tabular}

${ }^{\mathrm{a}}$ Based on t-test using separate variance estimation, 2-tailed tests; ${ }^{*} \mathrm{p}<.05$.

In summary, what I found with the t-test analysis of the survey data for younger residents in the Northwest neighborhood is relatively consistent with the expected community type of a "community of limited liability." Social relations and interaction with neighbors are performed less frequently and in a smaller networks than 15 years ago, and also the formal participation of young residents in the 
community decreased. The lower attachment to the neighborhood and neighbors corresponds to the picture of a "community of limited liability." Nevertheless, the neighborhood is very attractive as it is particularly perceived as a safe and kept up place. However, the satisfaction with certain neighborhood aspects was not found to be unequivocally heightened, but instead it was mixed. Specifically, dissatisfaction with the noise level and the traffic increased, which can be explained by the neighborhood's boosting attraction of outside persons by its growing number of bars, restaurants, and specialty shops on 23 rd and 21 st avenues.

The situation of older residents in the Northwest neighborhood was found to be different. My expectation of lower attachment and satisfaction of older people according to their, demographically, more marginal position in the neighborhood was not supported. Quite the opposite, older individuals and older couples were found to be more attached to the neighborhood and more satisfied with aspects of the physical and social environment than 15 years before. Their neighboring behavior did not change substantially, except that their network of known neighbors increased. More older residents participated formally in their community in 1993 compared to 1978. As did younger residents, older residents felt more safe and more secure from crime. Thus, the physical and social upgrading of the gentrification process did increase the neighborhood's image as a nice and secure place to live for residents in early as well as in advanced life-cycle stages, yet the mainly attracted demographic group of young people seems to rather form a "community of limited liability" with lower social contact and attachment, while the smaller proportion of older residents 
did not result in a marginal position of older people in the community, but in larger neighbor networks and greater attachment. This outcome may be due to generally longer residence in the neighborhood of older people and that they rather owned than rented their home. A correlational analysis showed that age was indeed significantly related to home-ownership $(p=.000)$ and years of residence $(p=.000)$ in that older residents were more likely to own their home and to have lived longer in the neighborhood than younger residents. A t-test analysis for residents of age 45 and older showed that in 1993 more of them owned their homes than 15 years before $(p=.009)$. The $t$-test also showed that older residents had not lived longer in the neighborhood in 1993 compared to 1978 (the mean years of residence was higher in 1993, but not on a statistically significant level). Therefore, I conclude that the increased home-ownership of older people in 1993 may be a major factor in their increased attachment to the neighborhood.

Single parents stand out from the other life-cycle groups, because they felt less secure from crime while all other groups felt significantly safer. This opposite result may be due to the low number of single parents $(n=4)$ in the survey in 1993, but the negative feeling of these single parents also shows that the neighborhood is not attractive to single parents anymore. While the survey in 1978 contained 22 single parents, in 1993 there were only four.

Status groups. As did Campbell and Lee (1990, 1992), I used the respondents' educational attainment and annual family income to determine their socio-economic status. What they found in their neighboring study (1990) and in 
their neighbor network study (1992) was a positive relationship between education as well as income, and network size. Guest and Lee's (1983b) "community of limited liability" is demographically characterized by high status residents. Since my analysis of the census data showed that there was an influx of highly educated and middle and upper-middle income people into the Northwest neighborhood, I expected to find in 1993, according to the mentioned findings of Campbell/Lee and Guest/Lee, overall more significant positive relationships between the two status variables, education and income, and the neighboring measures as well as the satisfaction and security measures than in the earlier period.

An analysis of Pearson's correlation coefficients for correlations of education with the neighboring, satisfaction, and attachment measures showed ${ }^{8}$ that education in 1993 was positively related (on a significant level of $\mathrm{p}<.05$ ) to formal participation in the neighborhood, i.e. volunteered time, to a safe feeling walking at day and at night on neighborhood streets, to satisfaction with lighting, transportation, and schools, to the frequency of discussions about politics with neighbors, and to the listing of attractive as well as unattractive neighborhood features. This was not the case 15 years before. Then, highly educated residents did not volunteer time to neighborhood organizations and were rather dissatisfied with lighting, though these relations were not statistically significant. However, the relationship between education and satisfaction with neighborhood schools was significant in 1978, but negative. All other relationships in 1993 had the same direction in 1978, but were

\footnotetext{
${ }^{8}$ For the exact numbers refer to table XXVII in appendix C.
} 
not significant. Only the likelihood to list attractive as well as unattractive neighborhood features correlated with education significantly in 1978, too.

In 1993, income was found to be positively related to most of the measures ${ }^{9}$. High income residents were found to have larger neighbor networks in comparison to lower income residents, to neighbor more frequently, to discuss all types of topics more frequently, to participate formally in the community more than lower income residents, to feel more safe walking from the car to the house at night, to be more satisfied with most of the given items, but less with property taxes, to have lived longer in the neighborhood, and to be more attached. Yet, higher income residents felt less secure from vandalism than lower income residents and were less alienated from people in general.

As for the case of education, this was not the same situation 15 years earlier. High income residents, then, had smaller neighbor networks than lower income residents, they neighbored less frequently, were less satisfied with housing, the neighborhood upkeep, transportation, shopping, and neighborhood parks, and discussed personal joys and shopping less frequently with their neighbors than lower income residents. However, none of these correlations were statistically significant at the .05 level, except the negative relationship between income and the number of neighbors visited inside each other's homes and the positive relationship between income and years of residence.

Most notable in this analysis are the changes in the direction of the

${ }^{9}$ For the exact numbers refer to table XXVIII in appendix C. 
associations between the status variables and the examined measures, though I have to be careful with the interpretation of the correlation coefficient for income, because the income variable had two additional categories in 1993 (i.e., the greater range of the variable probably influenced the magnitude of the correlation coefficient and the probabilities of significance). Also, the usage of Pearson's $r$ as a measure was problematic, because it is a measure for correlations between interval scaled variables, but most of the examined variables are ordinal.

The analysis showed that especially income had an impact on the residents' behaviors and attitudes toward the neighborhood. The results indicate for educated and high-income residents, as for the different life-cycles, a perception of the neighborhood as a safe and nice place. Further, the social upgrading that came with the physical renovation of the neighborhood seems to have increased social contacts and the attachment to the neighborhood of high status, specifically high income, residents. This may be due to a socially integrating effect of the demographic homogenization of the neighborhood. 


\section{CHAPTER VI}

\section{SUMMARY AND CONCLUSIONS}

The analysis of the census data showed that the four hypotheses proposed by Spain for gentrification activity in more recent times were not all supported for the case of the Northwest neighborhood in Portland, Oregon. Her first hypothesis of reduced gentrification activity due to the aging baby boomers could not be upheld, since, as in earlier stages of the gentrification process, the young were still the age group most attracted to the neighborhood. Spain further expected women to be more prevalent among the displaced than among the gentrifiers. I indeed found that poor women were displaced, but I also found that high income women played an important role as gentrifiers as there was an increase of women in general, of young, single women, and of single mothers. The finding of shorter commuting times for people living in the Northwest neighborhood compared to people living elsewhere in the city was consistent with Spain's hypothesis. However, I did not find increased racial heterogeneity in the Northwest neighborhood, but a stable racial composition of a about $94 \%$ white, $2 \%$ black, and $4 \%$ other race population, while the city of Portland became racially more diverse in the same time period.

The analysis showed also that most of the changes in socio-economic, compositional, and ecological characteristics of the Northwest neighborhood were 
consistent with the typically documented changes in gentrifying neighborhoods, where "the direction of change in revitalization areas parallels trends in the cities overall. But the rates of change in the revitalizing areas tend to be greater than those in their respective cities" (Gale 1984, p. 80). Specifically, the Northwest neighborhood showed a generally increased level of education, since $51 \%$ of the residents in 1990 had at least a college degree and the proportion of those with less than 9 years of schooling dropped to $3 \%$. The proportion of residents with professional, managerial, executive, and administrative occupations greatly increased and blue-collar workers in general were displaced. The median income in the Northwest neighborhood was still lower than in the city of Portland overall, but the income gap decreased, as more middle-income households moved into the neighborhood.

The population overall in the revitalizing area declined, which is consistent with documentations by Gale (1984). The analysis of census data showed that families in general and persons living alone were not attracted to the neighborhood, but the proportion of families with children at home increased sharply in the area indicating an advanced stage of gentrification. As the survey data demonstrated in addition, the main family form was the one of young families. The high increase in families with children questioned the role of the often documented importance of childless households with double incomes, the so called DINKS-households, in the gentrification process. However, I found a substantial increase in double income families in the Northwest neighborhood, which supported at least the importance of 
the dual earner portion of DINK for gentrification.

Another indicator for a more advanced stage of revitalization in the Northwest neighborhood was an increased residential stability in the area, as more people in 1993 had lived in the same house five years before than was the case in 1978. This furthermore rejected the hypothesis of a "back-to-the-city" movement in recent times superseding the "suburban dream" of the 1950s and early 1960s when the suburb, rather than the city, became the preferred place to live for many middle class families. The observed influx of younger middle class people in the 1970 s into old city neighborhoods led to the hypothesis of a movement from the suburbs back into the cities according to a rejection of suburban life of younger people and a new appreciation of urban life. However, gentrification research showed that most of the new-comers moved from within the city or even the same neighborhood, rather than from the suburbs. My results further emphasize this finding.

These findings for socio-economic, compositional, and ecological changes in the Northwest neighborhood are surprisingly consistent with Gale's (1980) original stage model of gentrification which was based on data from the 1960s and 1970s, but not with Spain's predictions for more recent times. It is further surprising, since gentrification was reported to be a "complex concept", not one process in different cities, different parts of the U.S., and different nations, yet Northwest Portland continued the generality of Gale's stage model.

To examine changes in interactional and symbolic features of the Northwest neighborhood, I first conducted t-tests with index variables from a neighborhood 
survey in 1978 and 1993. These tests did not result in many statistically significant differences. This lack of overall change in the interactional and symbolic fabric of community life is very surprising in the face of major compositional and physical change in the neighborhood, which is so often assumed to indicate social change as well. This assumption, in the case of Northwest Portland, is obviously incorrect.

Following t-tests with the component measures of the composite variables showed that survey respondents in 1993 were significantly more satisfied with the physical environment and security, but less satisfied with some of the available services in the Northwest neighborhood as compared to respondents in 1978. Further, respondents in 1993 had significantly fewer social contacts with their neighbors. All in all, the analysis indicated a perception of the Northwest neighborhood as a nicer and safer place than it was 15 years earlier.

T-tests for distinct life-cycle stages with the same variables resulted in different outcomes for young and old people. Young individuals, couples, and families in 1993 displayed fewer social contacts with their neighbors, had smaller neighbor networks, and participated formally not as much as the same life-cycle group 15 years earlier. However, young respondents in 1993 were more satisfied with some neighborhood aspects, but specifically less satisfied with noise level and traffic. In addition, they felt more secure in the neighborhood. These aspects indicated, as was found before for all persons, a perception of the Northwest neighborhood as a safe and well kept place. Along with the aforementioned lower attachment to the area and to neighbors, young people seemed to form a community 
that is consistent with the proposed model of a "community of limited liability." The elderly, in contrast, were found to be more attached, to have larger neighbor networks, and to participate formally in the community more than elderly respondents 15 years before. They also were more satisfied with the social and physical environment and felt more secure in the neighborhood. This result was not consistent with my expectations of lower satisfaction and attachment of older people according to their demographically more marginal position in the neighborhood. Further exploration showed that age was positively related to home-ownership on a significant level and that more older people owned their homes in the neighborhood in 1993 than in 1978. As was documented by earlier research, home-ownership has an important effect on social integration and attachment. This may have been a major factor in the increased attachment and satisfaction of older Northwest Portland residents.

Changes in the perception of single parents were outstanding, since they were the only group that felt less secure from crime than 15 years before. This may have been due to their low numbers in the survey and was indicative of the decreased attraction of this family type to the neighborhood in recent times.

The correlation analysis for status groups further sustained the major finding of a perception of the neighborhood as a nice and safe place to live, since also highly educated and high-income respondents showed this pattern of increased satisfaction and feeling of safety. Particularly in 1993 more than in 1978, highincome residents were found to have social contacts with their neighbors and to be 
attached to their neighborhood more than low-income residents. This outcome is the exact opposite of the usual assumption of the mass community approach of less local social contacts and attachment of high-income residents according to their greater resource of external relationships.

While I expected higher satisfaction in the advanced stage of gentrification, according to the "community of limited liability" model I did not expect more attachment, as was found for high-income and older residents in the neighborhood. However, the proportionally major group in the neighborhood, the young, showed lower attachment, consistent with my expectation. Although I did not examine the causes behind changed attachment levels, I would suspect that the demographic change, which made the neighborhood more status homogeneous, had an important socially integrating impact, especially on high income and older residents, consistent with Claude Fischer's notion of critical mass creating viable subcultures.

Now, it would be interesting to follow the further development of the Northwest neighborhood, as gentrification is judged more and more as a negative process for the area by many residents, as was documented in chapter III. Will the neighborhood association get active again, as it did before in the 1970s, to fight the new problems the neighborhood is facing, such as rising housing costs, displacement, traffic and noise? Which direction will the neighborhood take? This would be a question for future gentrification research, as many neighborhoods in the US that started revitalization in the late 1960 s and early 1970 s are now in more advanced stages of gentrification. Will they become even more upscale or will they 
loose their attractiveness? While I am writing this, Portland State University's Center for Urban Studies is conducting a survey, "Neighborhood Livability in Northwest Portland," funded by the City of Portland's Bureau of Licenses, concerning noise and traffic problems. Therefore, new activities to change the Northwest neighborhood are already underway. 


\section{REFERENCES}

Athanasiou, Robert and Gary A. Yoshioka. 1973. "The Spatial Character of Friendship Formation." Environment and Behavior 5: 43-66.

Austin, D. Mark and Yoko Baba. 1990. "Social determinants of neighborhood attachment." Sociological Spectrum 10: 59-78.

Beauregard, Robert A. 1986. "The Chaos and Complexity of Gentrification." Pp. 35-55 in Smith, Neil and Williams, Peter (eds.). Gentrification of the City. Boston: Allen \& Unwin.

Campbell, Karen E. and B. A. Lee. 1990. "Gender Differences in Urban Neighboring." The Sociological Quarterly 31: 495-512.

Campbell, Karen E. and B. A. Lee. 1992. "Sources pf Personal Neighbor Networks: Social Integration, Need, or Time?" Social Forces 70: 1077-1100.

Clay, Phillip L. 1979. Neighborhood Renewal. Lexington, MA: Lexington Books.

Clay, Phillip L. and Robert M. Hollister (eds.). 1983. Neighborhood Policy and Planning. Lexington, MA: Lexington Books.

Fischer, Claude S. 1973. "On Urban Alienations and Anomie: Powerlessness and Social Isolation." American Sociological Review 38: 311-326.

Fischer, Claude S. 1975. "Toward a Subcultural Theory of Urbanism." American Journal of Sociology 80: 1319-1341.

Gale, Dennis E. 1976. The back-to-the-city movement ... or is it?: a survey of recent homeowners in the Mount Pleasant neighborhood of Washington, D.C. Washington, D.C.: George Washington University, Department of Urban and Regional Planning.

Gale, Dennis E. 1980. "Neighborhood Resettlement: Washington, D.C." Pp. 95-115 in Laska, Shirley Bradway and Daphne Spain (eds.). Back to the City. Issues in Neighborhood Renovation. New York: Pergamon Press. 
Gale, Dennis E. 1984. Neighborhood Revitalization and the Postindustrial City. A Multinational Perspective. Lexington, MA: Lexington Books.

Gans, Herbert. 1962. The Urban Villagers: Group and Class in the City of Italian Americans. New York: Free Press.

Gans, Herbert. 1977. "Why exurbanites won't reurbanize themselves." New York Times, February 12, p. 21.

Greer, Scott. 1962. The Emerging City: Myth and Reality. New York: Free Press.

Guest, A. M. and B. A. Lee. 1983a. "Sentiment and evaluation as ecological variables." Sociological Perspectives 26: 159-184.

Guest, A. M. and B. A. Lee. 1983b. "The social organization of local areas." Urban Affairs Quarterly 19: 217-240.

Haggerty, Lee J. 1982. "Differential Social Contact in Urban Neighborhoods: Environmental vs. Sociodemographic Explanations." The Sociological Quarterly 23: 359-372.

Hamnett, C. 1984. "Gentrification and urban location theory: a review and assessment." Pp. 238-319 in Herbert, D. T. and Johnston, R. J. (eds.). Geography and the Urban Environment, Volume 6: Progress in Research and Applications. New York: John Wiley.

Herting, J. R. and A. M. Guest. 1985. "Components of satisfaction with local areas in the metropolis." The Sociological Quarterly 26: 99-116.

Hunter, Albert. 1974. Symbolic Communities: The Persistence of Change of Chicago's Local Communities. Chicago: University of Chicago Press.

Hunter, Albert. 1978. "Persistence of local sentiments in mass society." Pp. 133-162 in Street, D. (ed.). Handbook of Contemporary Urban Life. San Francisco: Jossey-Bass.

Hutchison, Ray. 1992. "Gentrification and the transformation of urban space." Research in Urban Sociology. Gentrification and Urban Change 2: 1-14.

Janowitz, M. 1967. The Community Press in an Urban Setting. Chicago: University of Chicago Press.

Kasarda, J. D. and M. Janowitz. 1974. "Community attachments in mass society." American Sociological Review 39: 328-339. 
Kerstein, Robert. 1990. "Stage Models of Gentrification. An Examination." Urban Affairs Quarterly 25:620-639.

Laska, S. B. and D. Spain. 1979. "Urban policy and planning in the wake of gentrification: anticipating renovators' demands." Journal of the American Planning Association 45: 523-531.

Laska, S. B. and D. Spain (eds.). 1980. Back to the City. Issues in Neighborhood Renovation. New York: Pergamon Press.

Lee, B. A. and A. M. Guest. 1983. "Determinants of Neighborhood Satisfaction. A Metropolitan-Level Analysis." The Sociological Quarterly 24: 287-303.

Lee, B., Spain, D., and D. Umberson. 1985. "Neighborhood revitalization and racial change: the case of Washington, D.C." Demography 22: 581-602.

Le Gates, Richard T. and Chester Hartman. 1981. "Displacement." Clearinghouse Review 15: 207-249.

Lynd, Robert S. and Helen Merell Lynd. 1929. Middletown: A Study in American Culture. New York: Harcourt, Brace \& World.

Lynd, Robert S. and Helen Merell Lynd. 1937. Middletown in Transition: A Study in Cultural Conflicts. New York: Harcourt, Brace \& Co.

Mantia. Patty. 1976. "A neighborhood of porch sitters: Residents of Victorian homes face contemporary problems with energy and good will." Willamette Week, July 12, p. 13.

Marans, R. W. and W. Rogers. 1975. "Toward an understanding of community satisfaction." Pp. 299-352 in A. Hawley and V. Rock (eds.). Metropolitan America in Contemporary Perspective. New York: Halstead.

Massey, D. and N. Denton. 1987. "Trends in the residential segregation of blacks, Hispanics, and Asians." American Sociological Review 52: 802-825.

McDermott, Judy. 1990. "Block Builders. One couple's energy, savvy and money paint a dazzling new face on Northwest Portland." The Oregonian, October 28 , p. L1.

McVea, Denise. 1992. "NW Portland struck hard by crime bite." The Oregonian, May 29, p. C1. 
Miller, F. D., Tsemberis, S., Malia, G. P., and D. Grega. 1980. "Neighborhood satisfaction among urban dwellers." Journal of Social Issues 36: 101-117.

Mills, C. A. 1988. "'Life in the upslope': the postmodern landscape of gentrification." Environment and Planning D: Society and Space 6: 169-189.

Moerer, Keith. 1983. "The New Neighbors. Recent commercial development brings growing pains to Northwest Portland. Now this city's livliest district must find ways to accomodate the old and the new." Willamette Week, December 6, p. 1.

Park, Robert E. 1915. "The City: Suggestions for the Investigation of Human Behavior in the City." American Journal of Sociology 20: 577-612.

Park, Robert E., Burgess, E. W., and R. D. McKenzie. 1925. The City. Chicago: University of Chicago Press.

Patterson, Rod. 1976. "There's certain charme present. NW Portland has local neighborhood atmosphere all its own." The Oregonian, August 8, p. B7.

Pattison, Timothy. 1977. The Process of Neighborhood Upgrading and Gentrification. M.A. thesis, Massachusetts Institute of Technology, Cambridge.

Pattison, Timothy. 1983. "The Stages of Gentrification: The Case of Bay Village." Pp. 77-92 in Clay, Phillip L. and Robert M. Hollister (eds.). Neighborhood Policy and Planning. Lexington, Ma: Lexington Books.

Perlman, Lee. 1974. "Neighborhood, industry on Northwest Portland plan: NWDA says 'downzone'; businessmen yell." Willamette Week, November 25, p. 2.

Perlman, Lee. 1992. "Residents air thoughts on Northwest Infill Plan." The Oregonian, November 23, p. B2.

Philliber, William W. 1976. "Prior Training, Opportunity, and Vested Interest as Factors Influencing Neighborhood Integration." Pacific Sociological Review 19: 231-244.

Pintarich, Paul. 1972. "Northwest Portland attempts to save urban neighborhood." The Oregonian, March 19, p. 1.

Portland (Or.) Bureau of Planning. 1975. Northwest District Policy Plan, adopted July 1975. Portland, OR: Bureau of Planning. 
Random House Webster's College Dictionary. 1992. New York: Random House.

"Residents of Northwest Portland seek neighborhood improvement." 1972. The Oregonian, March 19, p. 26.

Ringel, Norman B. and Jonathan C. Finkelstein. 1991. "Differentiating Neighborhood Satisfaction and Neighborhood Attachment Among Urban Residents." Basic and Applied Social Psychology 12: 177-193.

Rose, D. 1984. "Rethinking gentrification: beyond the uneven development of Marxist urban theory." Environment and Planning D; Society and Space 6: 169-189.

Rose, D. 1989. "A feminist perspective of employment restructuring and gentrification: the case of Montreal." Pp. 118-138 in Wolch, J. and M. Dear (eds.). The Power of Geography: How Territory Shapes Social Life. Winchester, MA: Unwin Hyman.

Simmel, Georg. [1905] 1950. "The Metropolis and Mental Life." Pp. 409-424 in Kurt H. Wolff (ed.). The Sociology of Georg Simmel. New York: Free Press.

Smith, N. 1987. "Of yuppies and housing: gentrification, social restructuring, and the urban dream." Environment and Planning D: Society and Space 5: 151172.

Smith, N. and P. Williams. (eds.). 1986. Gentrification of the City. Boston: Allen \& Unwin.

Spain, D. 1981. "A gentrification scorecard." American Demographics 3: 14-19.

Spain, D. 1992. "A Gentrification Research Agenda for the 1990s." Journal Of Urban Affairs 14: 125-134.

Spain, D., Reid, J., and L. Long. 1980. Housing Succession Among Blacks and Whites in Cities and Suburbs. U.S. Department of Commerce, Bureau of the Census, Current Population Reports, Special Studies Series P-23, no. 101, Washington D.C.

Stein, Maurice R. 1960. The Eclipse of Community. New York: Harper and Row.

Stinchcombe, Arthur L. 1968. Constructing Social Theories. New York: Harcourt, Brace \& World. 
St. John, Craig, Austin, D. Mark, and Yoko Baba. 1986. "The Question of Community Attachment Revisited." Sociological Spectrum 6: 411-431.

Suttles, G. D. 1972. The Social Construction of Communities. Chicago: University of Chicago Press.

Tönnies, Ferdinand. [1887] 1957. Community and Society. Translated by Charles P. Loomis. Michigan: Michigan State University.

U.S. Department of Housing and Urban Development. 1978. A survey of citizen's views and concerns about urban life. Washington, D.C.: U.S. Government Printing Office.

U.S. Bureau of the Census. 1983. 1980 Census of Population and Housing. Census Tracts, Portland, Oreg.-Wash., Standard Metropolitan Statistical Area, PHC80-2-290. Washington, D.C.: U.S. Government Printing Office.

U.S. Bureau of the Census. 1991. Statistical Abstract of the United States: 1991. Washington, D.C.: U.S. Government Printing Office.

U.S. Bureau of the Census. 1993. 1990 Census of Population and Housing. Population and Housing Characteristics for Census Tracts and Block Numbering Areas. Portland-Vancouver, OR-WA CMSA (Part), Portland, OR PMSA. CPH-3-266A. Washington, D.C.: U.S. Government Printing Office.

Varady, D. P. 1986. "Neighborhood confidence: a critical factor in neighborhood revitalization." Environment and Behavior 18: 480-501.

Warde, A. 1991. "Gentrification as consumption: issues of class and gender." Environment and Planning D: Society and Space 9: 223-232.

Warner, W. Lloyd. 1963. Yankee City. New Haven: Yale University Press.

Wirth, Louis. 1938. "Urbanism As a Way of Life." The American Journal of Sociology 44: 1-24.

Woolever, Cynthia. 1992. "A Contextual Approach to Neighborhood Attachment." Urban Studies 29: 99-116. 
APPENDIX A

\section{AGE COHORT TABLES}


TABLE XXIV

\section{ACTUAL AND EXPECTED NUMBERS OF PERSONS IN AGE COHORTS IN 1990 FOR THE CITY OF PORTLAND}

\begin{tabular}{|c|c|c|c|c|c|}
\hline Age cohort & $\#$ in 1980 & $\begin{array}{c}\text { Expected \# in } \\
1990\end{array}$ & $\begin{array}{c}\text { Actual \# in } \\
1990\end{array}$ & $\begin{array}{c}\text { Difference of } \\
\text { actual - } \\
\text { expected \# }\end{array}$ & $\begin{array}{l}\text { Ratio of } \\
\text { actual to } \\
\text { expected \# }\end{array}$ \\
\hline under 5 years & 23,810 & $* * * * * * *$ & 30,183 & $* * * * * *$ & $* * * *$ \\
\hline 5 to 9 years & 20,189 & $* * * * * *$ & 27,557 & $* * * * * *$ & $* * * *$ \\
\hline 10 to 14 years & 21,257 & 23,810 & 24,333 & +523 & 1.02 \\
\hline 15 to 19 years & 26,598 & 20,189 & 24,650 & $+4,461$ & 1.22 \\
\hline 20 to 24 years & 38,208 & 21,257 & 33,279 & $+12,022$ & 1.57 \\
\hline 25 to 34 years & 76,278 & 64,806 & 81,773 & $+16,967$ & 1.26 \\
\hline 35 to 44 years & 35,317 & 76,278 & 77,278 & $+1,000$ & 1.01 \\
\hline 45 to 54 years & 30,689 & 35,317 & 40,399 & $+5,082$ & 1.14 \\
\hline 55 to 64 years & 36,923 & 30,689 & 32,527 & $+1,838$ & 1.06 \\
\hline 65 to 74 years & 31,346 & 36,923 & 33,909 & $-3,014$ & 0.92 \\
\hline $\begin{array}{l}75 \text { years and } \\
\text { over }\end{array}$ & 24,436 & $* * * * * *$ & $* * * * * *$ & $* * * * * *$ & $* * * *$ \\
\hline 75 to 84 years & $* * * * * *$ & 31,346 & 21,989 & $-9,357$ & 0.70 \\
\hline $\begin{array}{l}85 \text { years and } \\
\text { over }\end{array}$ & $* * * * * * *$ & 24,436 & 7,538 & $-16,898$ & 0.31 \\
\hline
\end{tabular}

Source: Adapted from Census of Population and Housing, 1980, table P-1, and Census of Population and Housing, 1990, table1.

****** Not applicable 
TABLE XXV

ACTUAL AND EXPECTED NUMBERS OF PERSONS IN AGE COHORTS IN 1990 FOR THE NORTHWEST NEIGHBORHOOD

\begin{tabular}{|l|c|c|c|c|c|}
\hline Age cohort & $\#$ in 1980 & $\begin{array}{c}\text { Expected \# in } \\
1990\end{array}$ & $\begin{array}{c}\text { Actual \# in } \\
1990\end{array}$ & $\begin{array}{c}\text { Difference of } \\
\text { actual - } \\
\text { expected \# }\end{array}$ & $\begin{array}{c}\text { Ratio of } \\
\text { actual to } \\
\text { expected \# }\end{array}$ \\
\hline under 5 years & 64 & $* * *$ & 89 & $* * *$ & $* * *$ \\
\hline 5 to 9 years & 88 & $* * *$ & 86 & $* * *$ & $* * *$ \\
\hline 10 to 14 years & 99 & 64 & 64 & 0 & 1.00 \\
\hline 15 to 19 years & 126 & 88 & 136 & +48 & 1.55 \\
\hline 20 to 24 years & 446 & 99 & 376 & +277 & 3.80 \\
\hline 25 to 34 years & 1,204 & 572 & 1,045 & +473 & 1.83 \\
\hline 35 to 44 years & 429 & 1,204 & 896 & -308 & 0.74 \\
\hline 45 to 54 years & 279 & 429 & 356 & -73 & 0.83 \\
\hline 55 to 64 years & 360 & 279 & 186 & -93 & 0.67 \\
\hline 65 to 74 years & 353 & 360 & 167 & -193 & 0.46 \\
\hline 75 years and & 320 & $* * *$ & $* * *$ & $* * *$ & $* * *$ \\
\hline over & $* * *$ & 353 & 173 & -180 & 0.49 \\
\hline 75 to 84 years & $* * *$ & 320 & 106 & -214 & 0.33 \\
\hline $\begin{array}{l}85 \text { years and } \\
\text { over }\end{array}$ & & & & & \\
\hline
\end{tabular}

Source: Adapted from Census of Population and Housing, 1980, table P-1, and Census of Population and Housing, 1990, table 1.

*** Not applicable 
TABLE XXVI

\section{ACTUAL AND EXPECTED NUMBERS OF FEMALES IN AGE COHORTS IN 1990 FOR THE NORTHWEST NEIGHBORHOOD}

\begin{tabular}{|l|c|c|c|c|c|}
\hline Age cohort & $\#$ in 1980 & $\begin{array}{c}\text { Expected \# in } \\
1990\end{array}$ & $\begin{array}{c}\text { Actual \# in } \\
1990\end{array}$ & $\begin{array}{c}\text { Difference of } \\
\text { actual - } \\
\text { expected \# }\end{array}$ & $\begin{array}{c}\text { Ratio of } \\
\text { actual to } \\
\text { expected \# }\end{array}$ \\
\hline under 5 years & 31 & $* * *$ & 35 & $* * *$ & $* * *$ \\
\hline 5 to 9 years & 44 & $* * *$ & 48 & $* * *$ & $* * *$ \\
\hline 10 to 14 years & 46 & 31 & 39 & +8 & 1.26 \\
\hline 15 to 19 years & 55 & 44 & 64 & +20 & 1.46 \\
\hline 20 to 24 years & 221 & 46 & 190 & +144 & 4.13 \\
\hline 25 to 34 years & 524 & 276 & 487 & +211 & 1.76 \\
\hline 35 to 44 years & 168 & 524 & 424 & -100 & 0.81 \\
\hline 45 to 54 years & 126 & 168 & 160 & -8 & 0.95 \\
\hline 55 to 64 years & 189 & 126 & 90 & -36 & 0.71 \\
\hline 65 to 74 years & 222 & 189 & 92 & -97 & 0.49 \\
\hline 75 years and \\
over
\end{tabular}

Source: Adapted from Census of Population and Housing, 1980, table P-1, and Census of Population and Housing, 1990, table 1.

*** Not applicable 
APPENDIX B

CODEBOOK AND INDEX VARIABLES 


\section{CODEBOOK}

Variables Description

YRSRES Years of residence in the neighborhood

\section{Codes}

0 Less than 1 year

1 One year

22 to 5 years

36 to 10 years

411 to 98 years

1 Suburbs

2 Portland city

3 Different city in Oregon

4 Rural area in Oregon

5 Rural area outside of Oregon

6 City outside of Oregon

7 Town outside of Oregon

8 This neighborhood

0 None

1 One

2 Two

33 to 5

46 to 10

511 to 20

621 to 98

WAVE How often wave to neighbors?

1 Hardly ever

SPEAK How often chat outside with

2 Once a week

VISIT neighbors?

3 Several times a week

DISC

How often visit inside homes with neighbors?

4 Daily discussion with neighbors? 
Variables Description Codes

NSPK How many neighbors regularly chat 0 None

NVST with? 1 One

NDSC How many neighbors visit inside 2 Two homes? 33 to 4

How many neighbors have personal 45 to 8 talks with?

59 or more

FRND How many friends live in neighborhood?
0 None
1 Few
2 Half
3 Most
4 All

CSTFND What is the source of your closest friends?

1 Neighbors

2 Co-workers

3 Relatives

4 School/College

5 Other

HELPN Are neighbors helpful or look out for themselves?

1 Helpful

2 Look out

ADVN Would neighbors take advantage of you?

1 Would take advantage

2 Would be fair

1 Can be trusted

2 Cannot be trusted

ANOMIE Number of alienated responses from Actual number neighbors 
Variables Description

STAY Do you plan to stay in the neighborhood?

KEPTCH Would you keep in touch if moved away?

VSTNBR Would you return to visit if moved away?

CLUBS Number of neighborhood clubs/organizations belonged to

LEADC Number of leadership positions in neighborhood

VOLTME Have you volunteered time for neighborhood events?

CHRTY Have you worked for a charity fund drive in the nbd?

\section{Codes}

0 No

1 Yes
1-7 Actual number

88 and more
0 No

1 Yes

WLKDAY Feel safe walking in nbd in daytime?

WLKNIT Feel safe walking in nbd at night?

1 Very unsafe

CARTOH Feel safe going from car to house at

2 Unsafe night?

VSPARK Feel safe visiting nearest park?

3 Safe

4 Very safe

$\begin{array}{llll}\text { SHOU } & \text { Satisfaction with housing } & 1 \text { Very dissatisfied } \\ \text { SUPKE } & \text { Satisfaction with upkeep } & 2 \text { Dissatisfied } \\ \text { SANI } & \text { Satisfaction with animal control } & 3 \text { Satisfied } \\ \text { STFC } & \text { Satisfaction with traffic } & 4 \text { Very satisfied } \\ \text { SSEC } & \text { Satisfaction with security } & \\ \text { SNOIS } & \text { Satisfaction with noise level } & \\ \text { STRST } & \begin{array}{l}\text { Satisfaction with trust among } \\ \text { neighbors }\end{array} & \\ \text { SCOPS } & \text { Satisfaction with police protection } & \\ \text { SFIRE } & \text { Satisfaction with fire protection } & \\ \text { SLITES } & \begin{array}{l}\text { Satisfaction with street lighting } \\ \text { STRANS }\end{array} & \begin{array}{l}\text { Satisfaction with public } \\ \text { transportation }\end{array} \\ & \text { Satisfaction with neighborhood } \\ \text { SSCHL } & \text { schools }\end{array}$


Variables Description

SSHOP Satisfaction with shopping facilities

SPRKS Satisfaction with neighborhood parks

STAXS Satisfaction with property taxes

SPKNG Satisfaction with parking availability

BURG Security from burglary

VAND Security from vandalism

ASALT Security from assault

ROBRY Security from robbery

HARAS Security from harassment

JOYN How often discuss joys with neighbors?

POLN How often discuss politics with neighbors?

HMTN How often discuss home maintenance with neighbors?

PBLN How often discuss personal problems with neighbors?

SHOPN How often discuss shopping with neighbors?

ATTFEA Number of attractive neighborhood features listed

UNFEA Number of unattractive neighborhood features listed

HELPG Are people in general helpful?

ADVG Would people in general take advantage of you?

TRUSTG Are people in general trustworthy?

\section{Codes}

1 Very dissatisfied

2 Dissatisfied

3 Satisfied

4 Very satisfied

1 Very vulnerable

2 Vulnerable

3 Secure

4 Very secure
1 Never

2 Seldom

3 Occasionally

4 Frequently
1-7 Actual number 88 and more
1 Helpful

2 Not helpful

1 Take advantage

2 Be fair
1 Trustworthy

2 Not trustworthy 
Variables Description

ANOMEG Number of alienated reponses from people in general

MRST Marital status

OWNHME Do you own or rent your present home?

INCOME What was family income last year?

KIDS Number of children in the house

AGE How old were you on your last birthday?

EDUC Years of schooling
Codes

Actual number

0 Not married

1 Married

1 Own

2 Rent

1 Under $\$ 5,000$

$2 \$ 5,000$ to $\$ 9,999$

$3 \$ 10,000$ to $\$ 14,999$

$4 \$ 15,000$ to $\$ 24,999$

$5 \$ 25,000$ to $\$ 34,999$

$6 \$ 35,000$ to $\$ 49,999$

$7 \$ 50,000$ and up

Actual number

Actual age
1 None

2 Some grade school

3 Completed grade school

4 Some high school

5 High school graduate

6 Technical or vocational training

7 Some college

8 College graduate 
Variables Description

ACTIVTY What were you doing last week?
Codes

1 Worked full time

2 Worked part time

3 Unemployed

4 Keeping house

5 Retired

6 In school

7 Other 
INDEX VARIABLES

Index

variables

Description

Computed variables

PERSAFTY

Personal safety score

WLKDAY + WLKNIT + CARTOH+VSPARK

CRMSAFTY

Security with crime score

BURG + VAND+ASALT + ROBRY + HARAS

SATENV

Satisfaction score (physical environment and services)

SHOU +SUPKE + SANI +

STFC + SSEC + SNOIS + STRST + SCOPS + SFIRE+ SLITES+STRANS + SSCHL +SSHOP+SPRKS +STAXS + SPKNG

ATTRACT

Neighborhood

ATTFEA-UNFEA

attractiveness score

Satisfaction total score

PERSAFTY + CRMSAFTY + SATENV + ATTRACT

FMINTACT

Formal interaction score

CLUBS + LEADC + VOLTME+CHRTY

NFREQ

Neighboring frequency score

WAVE+SPEAK + VISIT + DISC

NEXTENT

Neighboring extensiveness NSPK + NVST + NDSC score 
Index

variables

NINTENS

IFINTACT

SOCINTEG

ALIENATN

ATTACHMT
Description

Neighboring intensiveness score

Informal interaction score

Social integration score

Alienation score

Attachment score
Computed variables

$(3 \mathrm{xPBLN})+(3 \mathrm{XJOYN})+$ $(2 \times P O L N)+$ HMTN + SHOPN

NFREQ+NEXTENT +

NINTENS+NBRKNO

FRND+YRSRES

ANOMIE+ANOMEG

STAY + KEPTCH + VSTNBR 
APPENDIX C

CORRELATION TABLES 
TABLE XXVII

STATISTICALLY SIGNIFICANT CORRELATIONS OF EDUCATION WITH NEIGHBORING, SATISFACTION, AND ATTACHMENT MEASURES IN 1993 COMPARED TO 1978

\begin{tabular}{|c|c|c|c|c|}
\hline \multirow[t]{2}{*}{ Item } & \multicolumn{2}{|c|}{ Pearson's $r$} & \multicolumn{2}{|c|}{ 1-tailed significance } \\
\hline & 1993 (n) & $1978(n)$ & 1993 & 1978 \\
\hline VOLTME & $+.1615(113)$ & $-.0254(101)$ & $.044^{*}$ & .401 \\
\hline WLKDAY & $+.1860(115)$ & $+.0879(102)$ & $.023^{*}$ & .190 \\
\hline WLKNIT & $+.2785(111)$ & $+.0144(102)$ & $.002^{* *}$ & .443 \\
\hline SLITES & $+.1624(115)$ & $-.1486(102)$ & $.041^{*}$ & .070 \\
\hline STRANS & $+.2931(114)$ & $+.0001(102)$ & $.001^{* *}$ & .500 \\
\hline SSCHL & $+.2835(110)$ & $-.1837(98)$ & $.001 *$ & $.035^{*}$ \\
\hline POLN & $+.2356(115)$ & $+.0381(97)$ & $.006^{* *}$ & .355 \\
\hline ATTFEA & $+.2051(112)$ & $+.2261(101)$ & $.015^{*}$ & $.011^{*}$ \\
\hline UNFEA & $+.2920(111)$ & $+.1923(102)$ & $.001^{* *}$ & $.026^{*}$ \\
\hline
\end{tabular}

$\mathrm{a}^{*} \mathrm{p}<.05 ;{ }^{-} \mathrm{p}<.01 ;-\mathrm{p}<.001$. 
TABLE XXVIII

STATISTICALLY SIGNIFICANT CORRELATIONS OF INCOME WITH NEIGHBORING, SATISFACTION, AND ATTACHMENT MEASURES IN 1993 COMPARED TO 1978

\begin{tabular}{|c|c|c|c|c|}
\hline \multirow[t]{2}{*}{ Item } & \multicolumn{2}{|c|}{ Pearson's r } & \multicolumn{2}{|c|}{ 1-tailed significance ${ }^{a}$} \\
\hline & 1993 (n) & 1978 (n) & 1993 & 1978 \\
\hline NBRKNO & $+.4756(108)$ & -.1320 ( 98$)$ & $.000^{-}$ & .097 \\
\hline WAVE & $+.2866(108)$ & $-.0101(100)$ & $.001^{-*}$ & .460 \\
\hline SPEAK & $+.4484(108)$ & $-.0197(99)$ & $.000^{-\infty}$ & .423 \\
\hline VISIT & $+.1790(107)$ & -.0104 ( 99) & $.033^{*}$ & .459 \\
\hline NSPK & $+.3970(108)$ & $-.1124(100)$ & $.000^{-}$ & .133 \\
\hline NVST & $+.2313(108)$ & $-.1989(99)$ & $.008^{-*}$ & $.024^{*}$ \\
\hline NDSC & $+.2634(108)$ & $-.1584(98)$ & $.003^{* * *}$ & .060 \\
\hline FRND & $+.2814(110)$ & $-.1101(100)$ & $.001^{* *}$ & .138 \\
\hline KEPTCH & $+.2144(108)$ & $+.0838(96)$ & $.013^{*}$ & .209 \\
\hline VSTNBR & $+.3468(110)$ & $+.0168(96)$ & $.000^{-}$ & .435 \\
\hline VOLTME & $+.2593(109)$ & $+.0181(98)$ & $.003^{*}$ & .430 \\
\hline CHRTY & $+.3173(106)$ & $+.1088(95)$ & $.000^{-1}$ & .147 \\
\hline CARTOH & $+.2064(110)$ & $+.0370(97)$ & $.015^{*}$ & .359 \\
\hline SHOU & $+.2246(109)$ & $-.0047(99)$ & $.009^{-1}$ & .482 \\
\hline SUPKE & $+.2263(110)$ & $-.0270(99)$ & $.009^{* *}$ & .395 \\
\hline SSEC & $+.2649(111)$ & $+.0459(99)$ & $.002^{-*}$ & .326 \\
\hline STRST & $+.3950(111)$ & $+.1547(98)$ & $.000^{-}$ & .064 \\
\hline SCOPS & $+.2923(111)$ & $+.1193(97)$ & $.001^{-}$ & .122 \\
\hline SFIRE & $+.2148(110)$ & $+.1130(99)$ & $.012^{*}$ & .133 \\
\hline STRANS & $+.1882(110)$ & $-.0424(99)$ & $.024^{*}$ & .338 \\
\hline SSCHL & $+.3133(106)$ & $+.0402(95)$ & $.001^{-}$ & .349 \\
\hline SSHOP & $+.1727(109)$ & $-.0291(98)$ & $.036^{*}$ & .388 \\
\hline SPRKS & $+.2005(111)$ & $-.0897(99)$ & $.017^{*}$ & .189 \\
\hline
\end{tabular}

$\mathrm{a} * \mathrm{p}<.05 ;{ }^{-} \mathrm{p}<.01 ;-\mathrm{p}<.001$. 
TABLE XXVIII, CONTINUED

STATISTICALLY SIGNIFICANT CORRELATIONS OF INCOME WITH NEIGHBORING, SATISFACTION, AND ATTACHMENT MEASURES IN 1993 COMPARED TO 1978

\begin{tabular}{llccc}
\hline Item & \multicolumn{2}{c}{ Pearson's r } & \multicolumn{2}{c}{1 -tailed significance } \\
& $1993(\mathrm{n})$ & $1978(\mathrm{n})$ & 1993 & 1978 \\
\hline STAXS & $-.2237(101)$ & $-.0687(86)$ & $.012^{*}$ & .265 \\
\hline SPKNG & $+.1986(110)$ & $+.1065(99)$ & $.019^{*}$ & .147 \\
\hline JOYN & $+.3318(111)$ & $-.0872(95)$ & $.000^{-}$ & .200 \\
\hline POLN & $+.3465(111)$ & $+.0059(95)$ & $.000^{-*}$ & .477 \\
\hline HMTNK & $+.4536(111)$ & $+.0620(92)$ & $.000^{-*}$ & .279 \\
\hline PBLN & $+.4264(111)$ & $+.0758(93)$ & $.000^{*}$ & .235 \\
\hline SHOPN & $+.2030(111)$ & $-.0518(93)$ & $.016^{*}$ & .311 \\
\hline ANOMEG & $-.1613(111)$ & $-.0028(100)$ & $.045^{*}$ & .489 \\
\hline YRSRES & $+.4659(110)$ & $+.2256(100)$ & $.000^{*}$ & $.012^{*}$ \\
\hline VAND & $-.1606(110)$ & $-.0819(99)$ & $.047^{*}$ & .210 \\
\hline
\end{tabular}

$\mathrm{a}{ }^{*} \mathrm{p}<.05 ;{ }^{-} \mathrm{p}<.01 ;-\mathrm{p}<.001$. 